ISSN: 0514-7336 — ISSN electrónico: 2386-3943

DOI: https://doi.org/10.14201/zephyrus202085109138

\title{
TRANSPORTE DEL MÁRMOL DE LAS CANTERAS DE ALMADÉN DE LA PLATA (SEVILLA) EN ÉPOCA ROMANA: EVALUACIÓN DE LAS RUTAS PROPUESTAS Y NUEVAS APORTACIONES MEDIANTE SIG
}

\section{Transport of marmora from Almadén de la Plata quarries (Seville) in Roman times: evaluation of estimated routes and new research approaches through GIS}

Diego Jiménez Madroñal*, Oliva Rodríguez Gutiérrez* y Joaquín Márquez Pérez**

* Dpto. de Prehistoria y Arqueología. Facultad de Geografía e Historia. cl Doña María de Padilla, s/n. 41004 Sevilla.Correo-e:djm11294@gmail.com; orodriguez@us.es.ID ORCID: https:/lorcid.org/0000-0003-3926-0945; https://orcid.org/0000-0001-6795-7868

** Dpto. de Geografía Física y Análisis Geográfico Regional. Facultad de Geografía e Historia. Cl Doña María de Padilla, s/n.41004 Sevilla. Correo-e: jmarper@us.es. ID ORCID: https://orcid.org/0000-0002-0252-3740

Recepción: 16/12/2019; Revisión: 23/02/2020; Aceptación: 28/03/2020

Resumen: En los últimos años se ha avanzado notablemente en la caracterización de los materiales lapídeos procedentes de las canteras béticas de Almadén de la Plata, Sevilla, tanto en lo referido a las áreas de extracción como a la distribución de sus productos. El presente trabajo se centra en el análisis de las rutas empleadas para el desplazamiento de la piedra desde la cantera hasta los principales puntos de embarque en el río Guadalquivir. Para ello, en una primera parte se revisan y valoran las propuestas presentadas hasta la fecha por los investigadores según diferentes evidencias y criterios. En un segundo momento se lleva a cabo, como alternativa hoy sometida a índices más objetivables, una propuesta de rutas óptimas por medio de la aplicación de Sistemas de Información Geográfica -sIG-. Todo ello, en cualquier caso, sirve para la reflexión sobre los diferentes parámetros que habrían condicionado el transporte de cargas pesadas en la antigüedad y nuestra mayor o menor capacidad para evaluarlos.

Palabras clave: materiales lapídeos; Baetica romana; transporte de cargas pesadas; rutas de coste mínimo; estudios interdisciplinares.

ABSTRACT: In recent years notable progress has been made in the characterization of stone materials from the Baetic quarries of Almadén de la Plata (Seville), both in terms of the areas of extraction and the distribution of their products. The present work focuses on the analysis of the routes used to carry the stone from the quarry to the main loading points on the Guadalquivir River. To this purpose, in the first part of the text, the proposals presented to date by the researchers are reviewed and evaluated according to different evidence and criteria. In a second part, a proposal of optimal routes is carried out using the application of Geographic Information System -GIS-, as an alternative method now subject to more objective measures. Ultimately, all this prompts some 
reflection on the different parameters that would have conditioned the transport of heavy loads in antiquity and our greater or lesser capacity to evaluate them.

Key words: ornamental stones; Roman Baetica; heavy load transport; Least Cost Paths; interdisciplinary studies.

\section{Introducción}

Las canteras y mármoles de Almadén de la Plata, Sevilla, están consideradas hoy entre las más importantes de la Bética (Mayer y Rodà, 1998: 218), aunque tradicionalmente han permanecido en un segundo plano por su más difícil identificación de visu en comparación con otros litotipos cuyo reconocimiento resulta más sencillo mediante análisis macroscópicos convencionales (Beltrán y Rodríguez Gutiérrez, 2010: 556). En los últimos años se ha avanzado en dos ámbitos fundamentales. Por un lado, en la aplicación de técnicas de análisis arqueométrico para la caracterización e identificación de litotipos, tanto de muestras tomadas en cantera como de los materiales arqueológicos identificados en destino ${ }^{1}$. Por otro, se ha intensificado tanto el trabajo de campo en las propias canteras a través de prospección selectiva del territorio ${ }^{2}$, como las intervenciones arqueológicas en frentes antiguos de extracción: Barranco de la Higuera (Taylor, 2015), Cerro de los Covachos (Rodríguez Gutiérrez et al., 2012) y Loma de los Castillejos (Ontiveros, 2008; Taylor, 2018). Además, en estos sectores se han hallado restos de productos manufacturados de época romana: escombreras de lascas, bloques abandonados y elementos arquitectónicos inacabados

1 Especialmente, en el marco de dos proyectos de investigación de $\mathrm{I}+\mathrm{D}+\mathrm{i}$ dirigidos por J. Beltrán (Marmora de la Hispania meridional-HAR2009-11438, 2010-2012 y Proyecto Marmora HAR20013-42078-P), en estrecha colaboración con el Instituto Andaluz del Patrimonio Histórico (IAPH), así como con la Unidad de Estudios Arqueométricos del ICAC de Tarragona.

2 Prospecciones desarrolladas en el marco de los proyectos citados, pero especialmente intensas en el marco de la tesis doctoral de R. Taylor: Las canteras romanas de mármol de Almadén de la Plata (Sevilla, España): un análisis arqueológico, presentada en 2015 en la Univ. de Sevilla (disponible en https://idus.us.es/handle/11441/28214; acceso 10/11/2019).
(Domínguez, 2008; Taylor, 2015). Así, se ha avanzado significativamente en el conocimiento de la explotación y uso del mármol de estas canteras en época romana, fechados en un prolongado período de tiempo que, al menos, abarcó desde época augústea hasta el s. III d. C. ${ }^{3}$.

Desde el punto de vista de su dispersión (Fig. 1), el uso del mármol de Almadén está documentado de forma mayoritaria en la cuenca navegable del Baetis, con un nodo de especial relevancia en Italica. No obstante, también estará presente en diferentes puntos de la costa atlántica de la Bética como Baelo Claudia (Beltrán et al., 2018), pero no en la mediterránea. Su radio de difusión se ha ampliado a medida que avanzan las investigaciones y se conocen mejor los litotipos, con posibles localizaciones ${ }^{4}$ fuera de los límites provinciales béticos, tanto en la Lusitania -para Augusta Emerita cf. Cisneros (1988: 106) - como en la Tarraconense - para Segobriga cf. Álvarez et al. (2008: 111); para Carranque $c f$. García-Entero y Vidal (2007: 62); para Pla de ses Figures, en Cabrera, cf. Álvarez et al. (2012: 428-429)-; incluso, aunque de forma más anecdótica, en ciudades de la Mauretania Tingitana -cf. Mayer y Rodà (1998: 218, n. 8) y Origlia et al. (2011)-.

En cualquier caso, la caracterización arqueométrica, ya consolidada en las actuales investigaciones,

3 Sobre este marco cronológico, véase Beltrán y Rodríguez Gutiérrez (2010: 561-563). Los principales hitos, por el momento, se encuentran en Italica, tanto al respecto de las más tempranas evidencias en el teatro en torno al cambio de Era como al funcionamiento de una statio serrariorum en época severiana (Rodà, 1997: 173-174; Beltrán y Rodríguez Gutiérrez, 2010: 563-564).

4 Y deben ser revisadas, en la medida en que algunas de estas identificaciones, especialmente durante los ańos ochenta y noventa, corresponden a un momento de aún no discriminación clara entre los materiales de Almadén y Estremoz, en la misma entidad geológica, Ossa Morena, pero un tanto alejadas entre sí tanto física como administrativamente (Lapuente et al., 2014: 334). 

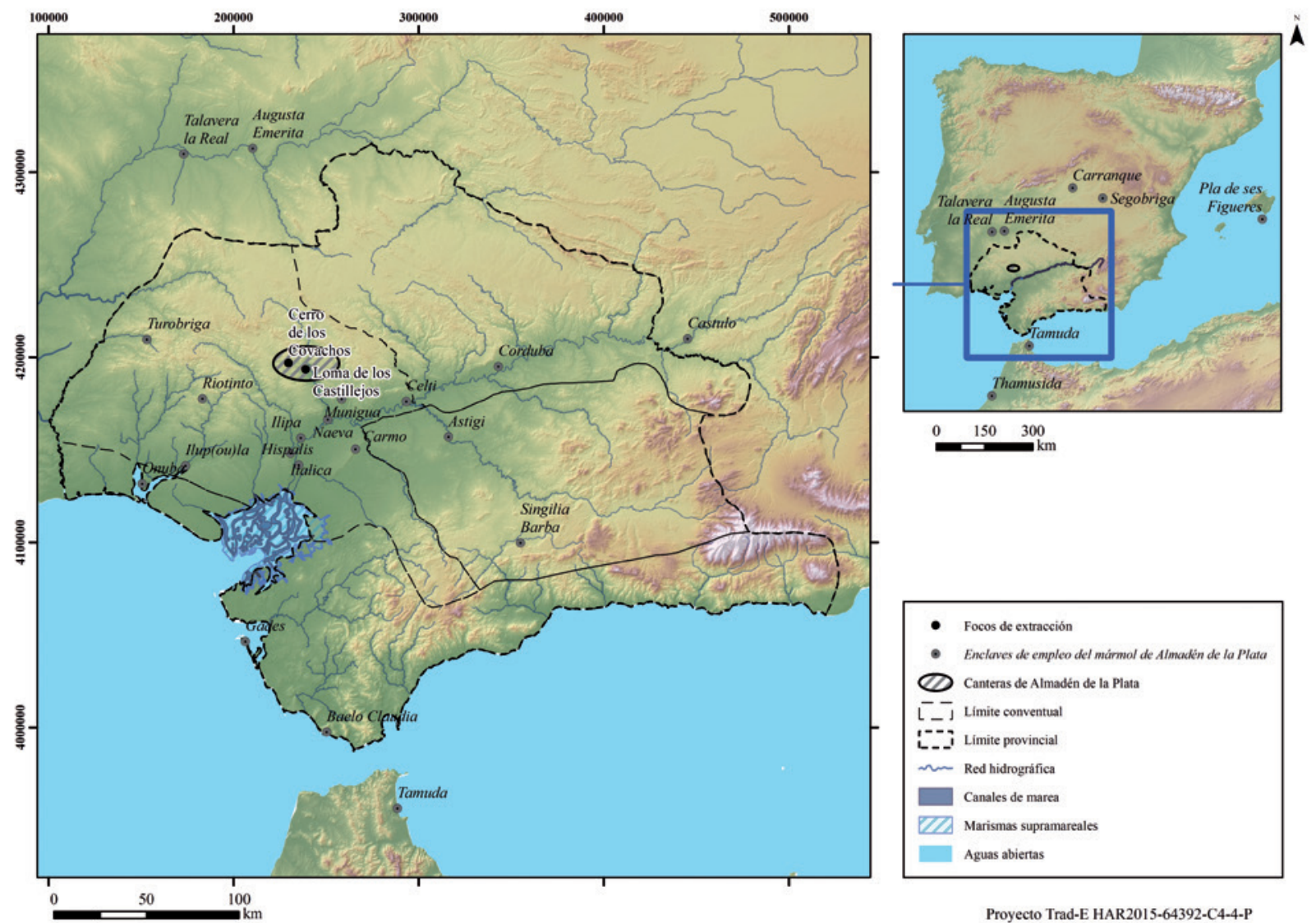

FIG. 1. Área de distribución del mármol de Almadén de la Plata.

debe ir más allá, tratando asimismo de servir de base para el estudio del sistema de distribución de los materiales lapídeos y, por ende, de las rutas seguidas por estos desde las zonas de extracción hasta los lugares de empleo (Beltrán y Rodríguez Gutiérrez, 2010: 557; Beltrán et al., 2012: 270). En el caso de los materiales de Almadén -a partir de diferentes reconstrucciones viarias (Sillières, 1990: 474-488; Corzo y Toscano, 1992: 174-178)-, se han propuesto las ciudades de Italica-Santiponce-, Naeva -Cantillana-e Ilipa-Alcalá del Río- como puntos de destino de los medios de transporte terrestre en el recorrido seguido desde los de extracción. Todas ellas, sobre el río Guadalquivir, serían eventuales candidatas para recibir los cargamentos pétreos y de ahí, por la vía fluvial, en ambos sentidos de la corriente, continuar el transporte. No obstante, esta compleja distribución cabe ser entendida, por tanto, en un sistema integrado de transportes donde se pretende conseguir la máxima rentabilidad ${ }^{5}$ por medio de la conexión entre los medios terrestres, fluviales y marítimos.

De este modo, el objetivo básico de este trabajo es evaluar la idoneidad de las rutas planteadas hasta el momento, junto a la de otras nuevas rutas generadas a partir de los Sistemas de Información Geográfica -SIG-, aplicando algoritmos de creación de superficies de coste mínimo acumulado-Acumulated

5 Duncan Jones (1974), Deman (1987) o Carreras y de Soto (2010) han establecido ratios de coste entre diversos modos de transporte. De estos trabajos se sirve el Stanford Geospatial Network Model of the Roman World (ORBIS), ideado por W. Scheidel y E. Meeks (disponible en https://orbis. stanford.edu; acceso 10/05/2019), que constituye el primer ejemplo para modelar la conectividad en el conjunto del imperio romano considerando tiempo y coste. 
Cost Surface, ACs- y de rutas óptimas - Least Cost Path, LCP-. Como Anderson (2012: 241) afirma “... los materiales que se encuentran en fuentes puntuales o con una distribución limitada son ideales para LCP...”, al igual que por su gran utilidad cuando se trata de "... reconstruir el trazado de caminos antiguos cuando solo se conocen los puntos de inicio y finalización..." (Herzog y Posluschny, 2011: 236).

\section{Estado de la cuestión}

\subsection{Patrones y rutas de transporte de los materiales}

2.1.1. Transporte terrestre del material marmóreo

Diferentes autores (Pegoretti, 1863; Landels, 1981) afirman que el suministro de los materiales pesados y voluminosos -entre los que se incluye el mármol- desde los centros de producción hasta los de empleo fue realizado mayoritariamente mediante carros de cuatro ruedas ${ }^{6}$ tirados por parejas de bueyes, unidos por medio de yugo y poste, y enganchados a los vehículos a través de arreos. Estos animales se empleaban, además de por su docilidad y estabilidad, por su excepcional capacidad de tracción (Raepsaet, 2002: 34). Así, el Codex Theodosianus (8.5.30) establecía una carga máxima para la angaria de 1.500 librae $-482,75 \mathrm{~kg}-$, mientras que el Edictum De Pretiis dioclecianeo recogía un peso de 1.200 librae -396 kg- para las raeda (Carreras, 1994: 26; DeLaine, 1997: 108). En cualquier caso, dado que la información contenida en estos documentos tendría otros objetivos, como los de garantizar la protección de las carreteras estatales -cursus publicus- y los transportes (Adams, 2012: 221), esos límites no necesariamente corresponderían a las capacidades máximas (Burford, 1960: 10; Raepsaet, 2010: 600).

6 Su estabilidad y facilidad de frenado hacían que en terrenos accidentados fueran preferidos a los de dos ruedas (Raepsaet, 2010: 592).
De esta forma, Sillières (1990: 745) y Russell (2013: 98) consideran que un solo par de bueyes puede llegar a movilizar hasta $800 \mathrm{~kg}$, y Bedon (1984: 139) y Raepsaet (1984: 116) elevan la capacidad de carga de una yunta a una tonelada. Con todo, el Manuale pratico per l'estimazione dei lavori architettonici, stradali, idraulici e di fortificazione (Pegoretti, 1863), evidencia preindustrial de estas prácticas, muy conservadoras desde época antigua, puede servir de referencia para fijar las cargas máximas de cada yunta. Así, en él se establecen diferentes capacidades de carga para cada par de bueyes según la pendiente del terreno: en zonas llanas o descendentes, de 2.750 a $3.000 \mathrm{~kg}$; del 4 al 5\%, $2.250 \mathrm{~kg}$; del 5 al 7\%, 1.750 kg; y del 7 al 9\%, $1.333 \mathrm{~kg}$.

Ante cargas muy pesadas e indivisibles -caso de bloques monolíticos de piedra- el número de yuntas podría incrementarse a fin de aumentar la capacidad de tracción (Pegoretti, 1863: 28). Existen ejemplos para la época moderna del transporte de un bloque de mármol de Carrara de $9 \mathrm{t}$ por medio de 12 yuntas (Rohault, 1874: 4-10 cit. Bedon, 1984: 138); el obelisco mussoliniano para el Foro Itálico, de 560 t, descendió desde las mismas canteras arrastrado por 60 yuntas (DeLaine, 1997: 99, n. 71). No obstante, con el incremento del número de parejas de bueyes también aumentaba la pérdida de eficiencia y coordinación (DeLaine, 1997: 99; Raepsaet, 2002: 26-27).

Frente a ello, los bueyes no son adecuados para climas extremos y son lentos (Russell, 2013: 100), si bien el factor tiempo en el mundo antiguo era relativamente menos importante que en la actualidad (Landels, 1981: 14). Además, cuando el desplazamiento se realiza en regiones montańosas, las velocidades disminuyen considerablemente debido a la carencia de un sistema de frenado en los carros que ayude a controlar la carga en un desnivel pronunciado (Landels, 1981: 177; DeLaine, 1997: 98), por lo que es necesario diferenciar entre las velocidades que se desarrollan en topografías llanas y en escarpadas. A ello se debe añadir que la jornada dedicada por los bueyes al transporte se ve reducida de manera sensible por el tiempo empleado en alimentarse de 


\begin{tabular}{|c|c|c|}
\hline AUTOR & VELOCIDAD & $\begin{array}{l}\text { Topografía DEL MEdIO } \\
\text { EN QUE SE PRODUCE } \\
\text { EL DESPLAZAMIENTO }\end{array}$ \\
\hline Landels (1981:177) & $1 \mathrm{mph}(1,6 \mathrm{~km} / \mathrm{h})$ & \multirow{4}{*}{$\begin{array}{l}\text { velocidades desarrolladas } \\
\text { en medios llanos }\end{array}$} \\
\hline Raepsaet (1984:134) & entre 2 y $2,5 \mathrm{~km} / \mathrm{h}$ & \\
\hline Pegoretti (1863: 24-25; 36-37) & $3 \mathrm{~km} / \mathrm{h}$ & \\
\hline Sippel (1987: 36) & $\begin{array}{c}\text { entre } 1 \text { y } 2 \mathrm{mph} \\
(1,6 \mathrm{~km} / \mathrm{h} \text { a } 3,2 \mathrm{~km} / \mathrm{h})\end{array}$ & \\
\hline Pegoretti (1863: 24-25; 36-37) & $2,8 \mathrm{~km} / \mathrm{h}$ & $\begin{array}{l}\text { velocidades desarrolladas } \\
\text { en pendientes descendentes }\end{array}$ \\
\hline Pegoretti (1863: 24-25; 36-37) & $\begin{array}{c}\text { entre } 1,8 \text { y } 2,25 \mathrm{~km} / \mathrm{h} \\
\text { (según la inclinación del } \\
\text { camino) }\end{array}$ & $\begin{array}{l}\text { velocidades desarrolladas } \\
\text { en pendientes ascendentes }\end{array}$ \\
\hline
\end{tabular}

FIG. 2. Valores de velocidad recogidos en el transporte con carros, según diferentes autores.

de la via Augusta, que, incluso al atravesar puertos alpinos, mantiene una pendiente entre el $7 \%$ y el $10 \%$. En cualquier caso, se observa cierta atención a las pendientes por las que deberán transitar los carros en caminos destinados al transporte de material marmóreo: valores máximos conocidos oscilan entre el $4 \%$ en las canteras de Chemtou (Russell, 2013: 101) y el 6\% en el

pasto y rumiarlo (Sippel, 1987: 36). Por otra parte, dado que las pezuñas de los bueyes son bastante frágiles y no disponen de buenas herraduras, deberían tener que desplazarse por caminos (Sillières, 1990: 749, n. 287). Landels (1981: 182) y DeLaine (1997: 98) también ven necesaria una infraestructura viaria, pero, en este caso, para permitir la circulación de los vehículos con ruedas, a menos que transiten por un terreno razonablemente llano (Fig. 2).

Adams (2001: 173), al referirse al Egipto romano, coincide con DeLaine (1997) en que en las calzadas por las que pudo transportarse el mármol de los Montes Porphyrites y Claudianus hay signos de pavimentación a fin de facilitar el paso de carros. Descarta que fuera una práctica generalizada si la plataforma natural era lo suficientemente dura como para permitir el acarreo. La solidez sería una de las cualidades buscadas en la construcción de caminos, de forma que se aprovecharían las zonas donde la dureza del sustrato geológico permitiera el adecuado paso de los bueyes, facilitando la circulación de los carros, sobre todo con cargas pesadas (Sippel, 1987: 36); en caso contrario, las ruedas podrían hundirse, como explica Vitruvio (10, 2, 11), referido a las obras del templo de Diana en Éfeso.

Por otra parte, Adams (2012: 221) y Russell (2013: 100) afirman que el desarrollo del sistema viario mejoró la eficiencia y la velocidad del transporte, aunque en unos rangos de pendiente asumibles por los carros. Paradigmático puede ser el caso diolkos del istmo de Corinto (Raepsaet, 2010: 592). Si atendemos a Pegoretti (1863: 24), se deduce que los carros no pueden superar pendientes superiores al $9 \%$.

\subsubsection{Vías de salida del material marmóreo}

Al estudiar las distintas posibilidades de salida desde Almadén de la Plata hasta los primeros puntos de recepción del material, se remite a vías terrestres y no fluviales: ninguno de los cursos fluviales que drenan el entorno de la explotación -fundamentalmente Viar y Rivera de Cala- pudieron usarse como vías de comunicación (Camacho et al., 2005: 293). En la década de 1990 fue presentada una serie de trabajos sobre el viario del sur peninsular (Sillières, 1990; Corzo y Toscano, 1992), incluyendo el tramo Italica-Emerita Augusta de la más conocida como Vía de la Plata. Este camino estaría directamente relacionado con las canteras de Almadén ya que, supuestamente, por él bajarían los mármoles allí extraídos hasta Italica. Para realizar las propuestas de trazado de dicha vía ( $\mathrm{Si}$ llières, 1990; Corzo y Toscano, 1992) se tuvieron en cuenta fuentes literarias y vestigios arqueológicos -calzadas, miliarios y puentes-. Ante la limitada fiabilidad de lo anterior, se empleó asimismo información sobre las rutas históricas para cruzar la sierra, como el Camino de la Plata (Sillières, 1990: 478; Corzo y Toscano, 1992: 174) y la carretera actual N-630 (Sillières, 1990: 479). 


\subsubsection{Las fuentes itinerarias}

El Itinerario de Antonino constituye la principal fuente de información sobre los caminos que atraviesan la Beturia (Corzo y Toscano, 1992: 52). En él, la vía Italica-Emerita Augusta forma parte del Iter $n .{ }^{\circ}$ XXIII (Ab ostio fluminis Anae Emeritam usque, $432,3-8)$. Incluye como hito de paso entre ellas el Mons Mariorum, que diferentes autores (Blázquez y Blázquez, 1921 cit. Taylor, 2015: 94; Canto, 197778) han localizado en el entorno de las canteras de Almadén. Establece la distancia entre Italica y Mons Mariorum en 46 millas -68 km- (Hernández Díaz et al., 1955: 248), cuando la distancia en línea recta es de $48,89 \mathrm{~km}$. Ante esta discrepancia, se propone, ya sea un desvío con respecto al trazado rectilíneo (Sillières, 1990: 475), cuando no el propio error en los datos consignados (Hernández Díaz et al., 1955: 248).

El Anónimo de Rávena difiere en los enclaves recorridos por la ruta $314,13-18$, dado que tras Curiga -Monesterio, Badajoz- incorpora Hilipa -Alcalá del Río, Sevilla- y luego Italica, omitiendo el Mons Mariorum; el camino se desviaba así hacia el este, tomando la orilla derecha del Guadalquivir (Sillières, 1990: 475; Corzo y Toscano, 1992: 173).

\subsubsection{Miliarios}

En total se conocen cinco hitos relativos a esta vía. El primero (García y Bellido, 1965: 17, pl. III; Corzo y Toscano, 1992: 172, fig. 92), alusivo a la milla xxv, se halló próximo al teatro de Italica $^{7}$. El segundo, de lectura más parcial, fue desplazado de su posición original y reutilizado en el Castillo de Guillena (Corzo y Toscano, 1992: 172, fig. 94). Ello hace poner en duda las primeras propuestas (Hernández Díaz et al., 1955: 249; García y Bellido, 1965: 22) de milla xxxi basadas en la distancia de $9 \mathrm{~km}$ (6 millas) entre Santiponce y Guillena. Criterios paleográficos llevan a Sillières (1990: 139140) y Corzo y Toscano (1992: 173) a identificarlo

7 Para Sillières (1990: 138) se encontraría en su posición original, mientras que Corzo y Toscano lo sitúan al norte del anfiteatro (1992: 174); el hallazgo, más tarde, de otro miliario, de nuevo en las proximidades del teatro, reforzaría esta última hipótesis. con la milla Xxi. A los ejemplares anteriores Corzo y Toscano (1992: 173-174) añaden otros tres: uno, también adrianeo, con la milla XXvI, encontrado in situ en el teatro de Italica en 1990; y otros dos, ya de cronología posterior -Constantino I y Galerio-, hallados, respectivamente, en Cantillana y Alcalá del Río. Ambos evidencian la relación de estos dos núcleos con el viario de la zona, si bien Corzo y Toscano (1992: 174) insisten en la imprecisión de su lugar de hallazgo.

\subsubsection{Evidencias arqueológicas de vías}

Solo se han conservado tramos de calzada ${ }^{8}$ en el entorno inmediato del teatro italicense (García y Bellido, 1960: 119; Sillières, 1990: 477), cuya entidad en el contexto de una red más amplia no ha podido ser establecida con claridad. Igualmente se ha de añadir un tramo dado como romano por Blázquez y Blázquez $(1921)^{9}$ al sur de Castilblanco de los Arroyos. Hernández Díaz et al. (1955: 249) y Corzo y Toscano (1992: 174, 176: fig. 97) definen como de época romana, a juzgar por las masas de hormigón desmembradas, el puente sobre la Rivera de Huelva, a pocos metros al oeste del actual y dentro del término municipal de El Ronquillo. Para Sillières (1990: 478-479) los vestigios corresponden a una construcción medieval o moderna. Corzo y Toscano (1992: 174) también identificaban como romano un puente al noroeste de la Algaba, ya destruido.

\subsubsection{Propuesta de rutas (Fig. 3)}

Lamentablemente (Taylor, 2015: 477), no se han identificado por el momento, en cantera,

8 M. A. Vargas (Carta Arqueológica de los términos municipales de Almadén de la Plata y El Real de la Jara. Memoria de Licenciatura inédita presentada en 1989 en la Univ. de Sevilla, p. 146 y Taylor (op. cit. n. 2: 261) documentan documenta en Almadén vestigios de calzada romana, concretamente en el yacimiento de Huerta de Catańo, que para Sillières (1990: 478) son restos del Camino de la Plata medieval.

9 Muñoz (2010: fig. 5) reproduce la antigua fotografía sin haber sido capaz de identificar in situ el tramo, quizá ya sepultado por la nueva carretera o dentro de fincas privadas ganaderas -paraje de Matute-. 
evidencias vinculadas con la salida del material, tales como, por ejemplo, zonas de almacenamiento de los bloques antes de su transporte o dedicadas a la estabulación y cuidado de los animales de carga. Ello explica que las diferentes propuestas sobre la evacuación del mármol de Almadén carezcan de evidencias arqueológicas para el trazado de la ruta desde el pie de las canteras, propiciando la multiplicidad de hipótesis.

A partir de los datos disponibles, los investigadores proponen diferentes rutas entre Italica y el puente de El Ronquillo (Hernández Díaz et al., 1955: 249) y entre el valle del Guadalquivir y Almadén de la Plata (Sillières, 1990; Corzo y Toscano, 1992), con las mayores divergencias en el tramo entre Italica y Castilblanco de los Arroyos. Sillières (1990: 483-484) entiende que el Camino de la Plata medieval reutilizó, de alguna manera, la vía romana que unía Italica y Emerita Augusta, que atravesó, entre otros puntos, la orilla derecha de la Rivera de Huelva, el camino de Guillena a Castilblanco, la carretera actual Almadén a Castilblanco -que sigue la divisoria de aguas entre el río Viar y Cala- o el yacimiento de Los Rincones hasta llegar a Almadén. Cree igualmente que este camino no estuvo empedrado, dado que casi en su totalidad se asienta "sobre la plataforma natural que generalmente es la roca” (Sillières, 1990: 763). Corzo y Toscano (1992: 174-177) optan por proponer dos caminos, coincidentes en el punto de origen -Almadén de la Plata-, pero con destino en núcleos distintos, lo que supone, en consecuencia, alternativas en los puntos de recepción de los mármoles. El primero de los senderos, el más empleado, toma la citada carretera entre Almadén y Castilblanco, para proseguir en dirección sureste hasta Naeva, donde finaliza tras pasar por el fortín de Mesa Redonda; el segundo coincide con el anterior hasta el Cortijo de Décima Primera, cruza la Rivera del Cala buscando el Palacio de Parladé, para dirigirse en dirección W-SW y atravesar el puente de El Ronquillo; de allí sale en dirección a El Garrobo, pasa por el Cortijo del Esparragal y finaliza en Italica. La restitución del trazado de la vía romana hasta el puente de El Ronquillo propuesta por Hernández Díaz et al. (1955: 249) coincide con el camino occidental de Corzo y Toscano (1992: 177). No obstante, emplea el actual camino viejo de Santiponce hasta Guillena, desde donde se dirige a Las Pajanosas y de allí se aproxima a la actual carretera de Extremadura. Tanto Hernández Díaz et al. (1955: 250) como Corzo y Toscano (1992: 177-178) atribuyen al emperador Adriano el tramo Italica-Puente de El Ronquillo ${ }^{10}$, en uso hasta el s. III d. C. En este punto se retomaría el camino oriental por la rotura del puente, lo que parece corroborar la ya citada incorporación de Ilipa al Ravennate (Taylor, 2015: 97).

\subsubsection{Propuesta de hitos receptores del mármol}

La primera hipótesis se debe a Canto (1977-78), para quien los materiales tuvieron dos salidas: una principal hasta Italica a través del Iter XXIII del Itinerario de Antonino; y otra secundaria hacia Ilipa, a través de cuyo puerto se organizaría el comercio fluvial de los mármoles. Posteriormente, Sillières (1990: 763) insistió en Italica e Ilipa como núcleos exportadores del mármol de Almadén de la Plata, mientras que Corzo y Toscano (1992: 177) matizaron esta idea, al señalar que en época imperial Italica, al distanciarse del río por dinámicas sedimentarias ${ }^{11}$, cedería el papel portuario del comercio a Ilipa. Hasta ese momento, por tanto, habría funcionado como una suerte de 'marmorata italicense' (Canto, 1977-78: 178), donde se recibían los mármoles para ser trabajados en un taller o statio serrariorum, siendo el único puerto fluvial (García y Bellido, 1960: 118; Bonsor, 1989: 82) de la provincia Baetica donde se ha confirmado su existencia (Rodà, 1997: 174; Rodríguez Gutiérrez et al., 2012: 649). Cisneros (1988: 106), ante la concentración de mármoles de Almadén en Itálica, propone también su inicial recepción en la citada statio, para luego redistribuirse a través del curso del Baetis.

10 Sillières (1990: 761-762) propone solo su remodelación en tiempos adrianeos, ante las necesidades de abastecimiento de material marmóreo con motivo de las obras de ampliación de la ciudad.

11 Taylor (2015: 97) pone en duda este argumento paleohidrográfico teniendo en cuenta la existencia de una supuesta statio marmorariensis severiana en las proximidades del luego monasterio de San Isidoro. 


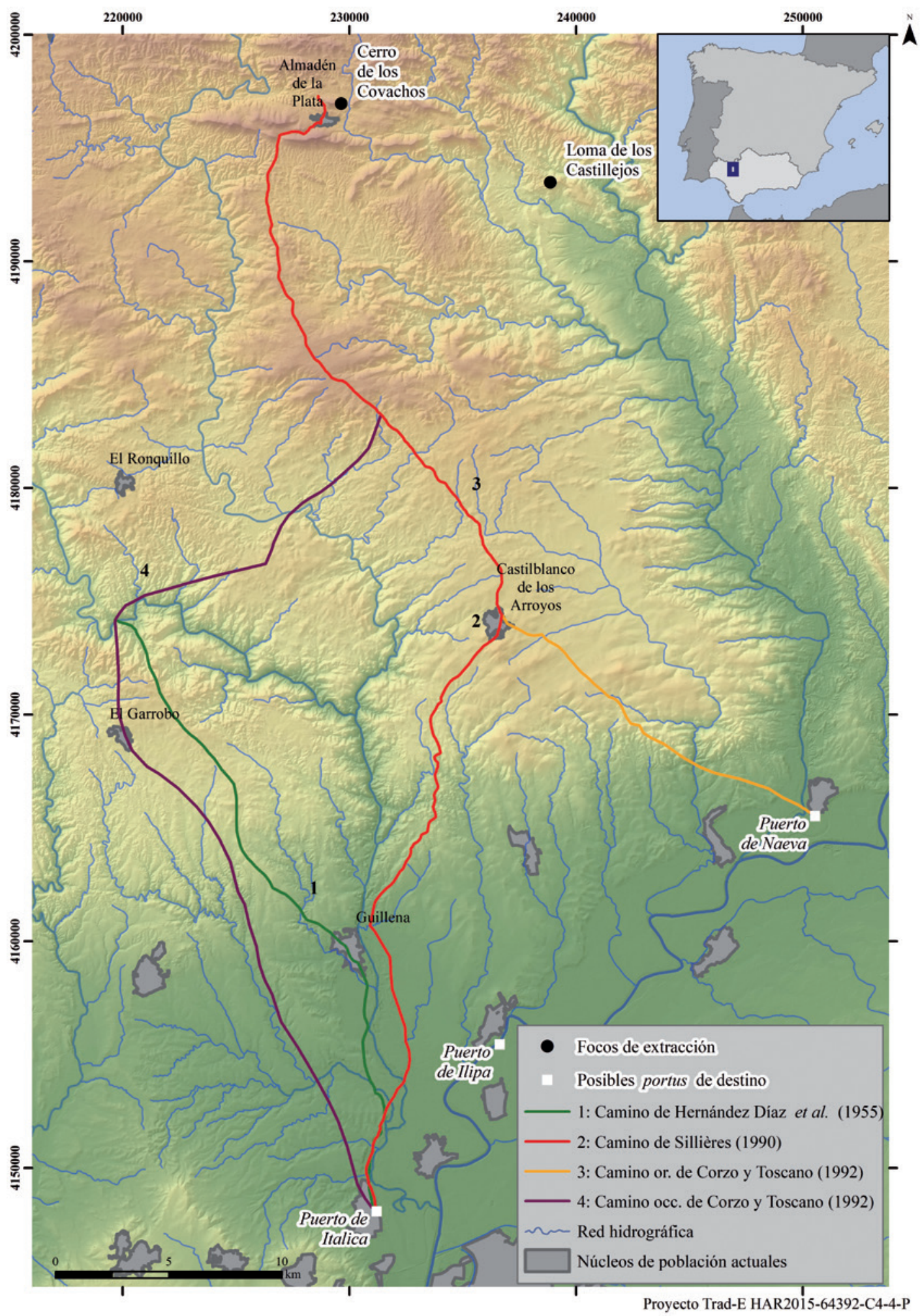

FIG. 3. Propuestas viarias entre Almadén de la Plata y el valle del Guadalquivir. 
Frente a ello, en las últimas investigaciones sobre los mármoles de Almadén (Padilla, 1998: 300; Beltrán y Rodríguez Gutiérrez, 2010: 561), y debido a la identificación de la Loma de los Castillejos como frente de explotación antiguo, cobra fuerza la hipótesis de que la salida del material marmóreo desde las canteras hacia el sur se realizara por una vía terrestre (propuesta por Corzo y Toscano, 1992: 174-178) hasta Naeva, con importante puerto fluvial (Bonsor, 1989: 80).

En cambio, Taylor (2015: 497) es partidaria de una distribución diferenciada de los mármoles extraídos de las canteras en función de su ubicación, $\mathrm{y}$, por tanto, de la vía de salida terrestre más viable, sugiriendo que el eje Almadén-Castilblanco fuera empleado para el transporte de los materiales del Cerro de los Covachos; el eje Almadén-Viar -y luego valle del Viar- por la Loma de los Castillejos; y ambas salidas para el Barranco de la Higuera.

\subsection{Aplicación de los SIG al trazado de rutas óptimas}

\subsubsection{Superficies de costes mínimos acumulados y rutas óptimas}

La aplicación de los sig para calcular el trazado de vías de comunicación total o parcialmente extintas se fundamenta principalmente en el algoritmo de caminos mínimos de Dijkstra (1959), empleado para determinar la ruta más corta entre nodos en un grafo. Tomlin y Berry (1979) incluyeron algoritmos para calcular superficies de coste acumulado y rutas óptimas en el programa MAP - Map Analysis Package- en 1980, predecesor de los que a finales de esa década y principios de la siguiente fueron ya programas sig de amplia difusión -Grass, Idrisi, o ArcInfo-.

La generación de superficies de costes mínimos acumulados se lleva a cabo en el modelo de datos raster mediante la caracterización de las celdillas de la zona de estudio a partir de valores que representen la fricción que supone atravesarlas; los algoritmos calculan entonces el ACS para ir desde una o varias celdillas de origen a las restantes multiplicando el valor de cada celdilla por la longitud de la ruta que lo atraviesa. La ruta óptima hacia una celdilla concreta la conforman aquellas cuya suma supone el coste mínimo para alcanzarla, y puede conocerse a partir de un segundo raster, donde se asigna a cada celdilla un valor que, a modo de aguja de brújula, indica cuál de las que la rodean fue la seguida para alcanzarlo.

\subsubsection{Superficies de fricción: la pendiente}

La fricción que indica el coste de atravesar cada celdilla se obtiene a partir de la combinación de una serie de factores que favorece o restringe el movimiento: entre ellos la pendiente suele ser el más empleado, tanto por su importancia en relación al resto (Kvamme, 1992; Jobe y White, 2009), como por la relativa facilidad de su cálculo a partir de un modelo digital de elevaciones -MDE-; sin embargo, la pendiente es un factor muy peculiar: afecta de forma distinta en función de la dirección en que es afrontada -no es lo mismo subirla que bajarla-, no tiene un comportamiento lineal -multiplicar por dos la pendiente supone más que duplicar la fricción-, tampoco suele ofrecer valores de pendiente efectivos -es decir, no se suele calcular en función de la dirección del movimiento- y es muy dependiente de la resolución espacial de la celdilla -que puede no capturar adecuadamente cambios altimétricos que tengan lugar en pequeñas distancias-. Otros factores que suelen ser considerados para generar una superficie de fricción son la red fluvial -por la dificultad que suele suponer atravesarla, especialmente en determinadas épocas- y el tipo de suelo -lodazales o zonas pantanosas suelen ser esquivadas- (White, 2012; Verhagen et al., 2019).

\subsubsection{Tiempo vs. energía: las unidades para medir la fricción}

Existen funciones para calcular tanto el tiempo como el esfuerzo de atravesar una celdilla; entre las primeras se encuentran las de Naismith (1892), Ericson y Goldstein (1980), Langmuir (1984) o Tobler (1993), mientras que para calcular el gasto energético han sido propuestas funciones por 
Pandolf et al. (1977), Rees (2004), Llobera y Sluckin (2007) o Herzog (2013b). Las unidades de tiempo son más fáciles de comparar y entender y, sin embargo, se prefieren las relativas al gasto energético porque suponen una medida del esfuerzo para mantener una cierta velocidad. Por otra parte, el desgaste energético requiere recobrar fuerzas mediante comida y descanso, de modo que se pone un límite al tiempo que se puede estar en movimiento y, por tanto, a la distancia recorrida (Verhagen et al., 2019). En cualquier caso, existen fórmulas para su conversión (Leuthäusser, 2013; Groenhuijzen y Verhagen, 2015).

\subsubsection{ACS, LCP y validación de sus resultados}

En el contexto del cálculo de rutas óptimas referidas a épocas pretéritas, hay que tener en cuenta un factor clave: la superficie del terreno y los usos que sobre ella se asientan, debido tanto a procesos naturales como antrópicos, pudieron ser muy diferentes de los actuales. Si la información disponible para su estudio, especialmente la altimetría obtenida hoy día por medio de sensores de alta resolución, no refleja con fidelidad la que había en los momentos en que estas rutas fueron creadas y utilizadas, es necesario dotar de alguna garantía los resultados obtenidos y para ello se hace necesario buscar algún medio de validación. Por otra parte, los algoritmos informáticos actuales posibilitan, en cada paso del proceso de generación de las rutas óptimas, una serie de opciones que consiguen que sus resultados puedan llegar a ser muy diferentes incluso a pesar de partir de los mismos datos.

En general, la validación se basa en características de la ruta en sí -longitud, pendiente o sinuosidadque permiten conocer su eficiencia, así como en su relación con evidencias disponibles - distancia a restos arqueológicos coetáneos, por ejemplo-, cuya diversidad y número incrementan la probabilidad de que la ruta sea correcta. En este sentido, la ponderación de estos elementos es un factor clave que suele basarse en el juicio de expertos, y que se puede resolver mediante la comparación por pares (Saaty, 1980) para dotar de consistencia al resultado.

\subsubsection{LCP y vías romanas para el transporte de materiales}

En relación con las hipótesis acerca del trazado de vías romanas destinadas principalmente al transporte de materiales, existe cierta experiencia en el estudio tanto de las vías de salida del material lapídeo a través de metodologías más tradicionales ( $\mathrm{Pa}-$ dilla, 1998; Adams, 2001; Russell, 2013) como de movilidad aplicada a problemas de índole arqueológica por medio de los sig. Constan ensayos con monumentos, caminos y vías pecuarias de tiempos prehistóricos (Wheatley et al., 2010; Murrieta-Flores, 2011), así como del estudio de vías romanas, ya sea al respecto de los factores que determinaron su trazado (Güimil y Parcero, 2015; Fonte et al., 2017) como de la reconstrucción de itinerarios concretos (Herzog, 2013a; Verhagen y Jeneson, 2012). Asimismo, se va incrementando el número de investigaciones que emplean los SIG para profundizar en el transporte de materias primas en época preindustrial (Rademaker et al., 2012; Groenhuijzen y Verhagen, 2015), si bien faltan trabajos que se sirvan de ellos para el estudio del transporte de cargas pesadas.

\section{Datos}

Las fuentes de información empleadas en este ensayo se pueden clasificar en dos grupos: las que posibilitan la generación de la superficie de coste mínimo acumulado y rutas óptimas - MDE, red fluvial, vados y puentes, puntos de origen y destino- $y$ las que permiten caracterizarlas y validarlas -asentamientos, vías pecuarias, etc.-.

\subsection{Información necesaria para generar una ruta de minimo coste acumulado}

a) Modelo Digital de Elevaciones -MDE-: un dato imprescindible para obtener una ruta óptima en función de la topografía es el MDE; de él pueden extraerse la pendiente del terreno y una red fluvial acorde con el relieve circundante. 
Dada la importancia del MDE, en su selección habrá que atender a su calidad en términos de precisión posicional, tanto en relación con la resolución espacial, como con el grado de similitud entre los valores estimados y reales.

En el caso de un estudio sobre tiempos pretéritos es preciso tener en cuenta la calidad temporal de los datos, ya que las eventuales transformaciones sufridas con el paso del tiempo -procesos de erosión, deforestación, urbanización, construcción de carreteras, etc. - influyen de manera decisiva en la variación de la variable altitud. Una alteración muy relevante en la zona de estudio ha sido la construcción del embalse de Melonares (2002-2007). De esta forma, si se trabaja con los MDE generados a partir de la situación geográfica actual -de $5 \mathrm{~m}$ del IGN de 2014-15 y de 10 m del Instituto de Estadística y Cartografía de Andalucía (IECA), de 2008-09-, se observa que ni existe una correspondencia con la topografía de época romana, lo cual requeriría datos paleoambientales precisos provenientes de estudios geomorfológicos y geológicos, ni se consigue siquiera de forma aproximada en la zona afectada por el embalse. Por tanto, es imprescindible disponer de un MDE anterior a la construcción del embalse para que la topografía no constituya una fuente de error en el análisis. Así, se ha optado por emplear el MDE de $10 \mathrm{~m}$ de resolución espacial generado por las Consejerías de Obras Públicas y Transportes, Agricultura y Pesca, y Medio Ambiente de la Junta de Andalucía (2005) a partir de fotografías aéreas de 20012002 a escala $1: 20.000^{12}$.

b) Puntos de origen y destino: las rutas modeladas parten de las canteras en las que se han hallado restos de explotación antigua con total seguridad, es decir, el Cerro de los Covachos y la Loma de los Castillejos (Taylor, 2015: 457), y se dirigen hacia los núcleos barajados en las

12 https://www.juntadeandalucia.es/medioambiente/site/rediam/menuitem.04dc44281e5d53cf8ca$78 \mathrm{ca} 731525 \mathrm{ea} 0 /$ ?vgnextoid=0849f1 ea90891110VgnVCM1000000624e50aRCRD; acceso 09/07/2019. hipótesis como puntos de destino -Italica, Ilipa y Naeva-, todos ellos de carácter portuario.

c) Vados y puentes: además de los puentes de época romana ya citados -El Ronquillo y La Algaba-, han sido digitalizados dos vados en el curso medio y bajo del río Viar: el vado de las Contiendas y el vado de los Pinos; y otro en la Rivera de Huelva, el vado de las Palomas, entre Guillena y Castilblanco.

d) Red fluvial: capa lineal extraída de los Datos Espaciales de Referencia de Andalucía -DERA- ${ }^{13}$, escala 1:100.000, pero basada en los datos de la cartografía topográfica 1:10.000 ${ }^{14}$. Dispone de atributos sobre tipología y jerarquía.

\subsection{Otros datos}

a) Asentamientos intermedios entre orígenes y destinos: se han digitalizado todos los núcleos datados como de época romana ${ }^{15}$ ubicados en la margen derecha del Guadalquivir hasta Almadén de la Plata.

- Los núcleos más próximos al curso del Guadalquivir han sido digitalizados a partir de Ponsich (1974), quien realizó prospecciones arqueológicas en el entorno del Bajo Guadalquivir.

- En el caso de Alcalá del Río y Castilblanco de los Arroyos, además de las prospecciones arqueológicas (Ponsich, 1974 y Camacho et al., 2005, respectivamente), la información arqueológica se ha visto completada con los trabajos posteriores desarrollados para la elaboración de la Carta Arqueológica Municipal, en el primer caso, y por la revisión del

13 https://www.juntadeandalucia.es/institutodeestadisticaycartografia/DERA/g03.htm; acceso 09/07/2019.

${ }_{14}$ No obstante, la red fluvial también participa en la caracterización de las rutas, en concreto, mediante el número de intersecciones con las rutas generadas.

15 En los casos en los que la referencia temporal aparece con mayor precisión, es decir, diferenciada en Alto y Bajo Imperio, se han incorporado solo los fechados en el primer período, al coincidir en gran medida con el de explotación de las canteras. 
PGOU -en fase de aprobación provisional-, en el segundo ${ }^{16}$.

- En la zona de afección del embalse de Melonares -términos de Almadén de la Plata, El Pedroso y Castilblanco de los ArroyosGarcía Sanjuán et al. (2004) llevaron a cabo una prospección arqueológica superficial y Fernández Flores y Carrasco (2013-2014) intervenciones arqueológicas.

- Por último, Vargas ${ }^{17}$ (1989), citado en Taylor (2015), realizó una prospección arqueológica superficial para elaborar la Carta Arqueológica de los términos municipales de Almadén de la Plata y El Real de la Jara.

b) Viario: las carreteras y caminos -donde se incluyen las vías pecuarias- proceden de la Base Cartográfica de Andalucía básica ${ }^{18}$, elaborada por el IECA a escala 1:10.000, así como del DERA ${ }^{19}$, en el caso de las carreteras.

\section{Metodología}

El proceso metodológico, para el que se ha empleado básicamente el programa ArcGis versión 10.4.1, consta de tres fases principales: la creación de la superficie de fricción; la obtención de las superficies de coste mínimo acumulado y generación de las rutas óptimas, y, finalmente, la comparación y validación de las rutas.

\subsection{La creación de la superficie de fricción}

Caracterizar cada celdilla de una capa raster mediante valores que indiquen la dificultad de atravesarla supone generar una superficie de fricción; la

16 Agradecemos a M. Oria Segura el haber podido acceder a la información inédita generada en el proceso de elaboración de dicho documento.

17 Vargas, op. cit. n. 8.

18 https:/www.juntadeandalucia.es/institutodeestadisticaycartografia/bcadescargas/; acceso 10/07/2019.

19 https://www.juntadeandalucia.es/institutodeestadisticaycartografia/DERA/g09.htm; acceso 10/07/2019. pendiente y la red fluvial son dos de las variables más empleadas en esta labor.

En el modelo de datos raster la pendiente puede ser generada a partir de diferentes métodos; aquí se ha optado por el de Horn-también conocido como operador de Sobel- debido a que también es el empleado en algunos de los paquetes sig más conocidos -Arcgis, Grass, Qgis, etc.-. Por otra parte, hay que considerar un umbral de pendiente máxima a partir del cual el desplazamiento mediante carros tirados por bueyes es difícil -especialmente si van cargados con grandes pesos-, y que estudios previos estiman en un 9\% (Pegoretti, 1863: 24). Por esta razón, la pendiente original ha sido modificada de dos formas diferentes: mediante el método propuesto por Herzog ${ }^{20}$ (2013a) en el que los valores inferiores al umbral oscilan entre 1 y 2 , y los superiores se ven incrementados de forma exponencial; el segundo método se lleva cabo a partir de multiplicar los valores superiores al umbral por una constante -10 y $100-$. Por lo tanto, estos procedimientos dan lugar a tres tipos de superficies.

El tratamiento de la red fluvial es más complejo: se parte de que la dificultad inherente a atravesarla depende más de su caudal que de su jerarquía, por lo que importa calcular este valor en cada punto de la red fluvial mediante la aplicación de funciones hidrológicas a un MDE; sin embargo, la red extraída de un MDE no es tan precisa como la que puede aportar una cartografía de detalle:

- En la red extraída del mDE la planimetría puede variar en función de procesos previos como el relleno de depresiones -artificiales o no- o el tipo de algoritmo empleado para la generación de las direcciones; su precisión depende de la resolución espacial del MDE y, en última instancia, el modelado hidrográfico superficial da como resultado una red de cauces por la que en realidad puede o no circular el fluido, en función de sus características litológicas.

- La red extraída de la cartografía de detalle refleja adecuadamente la planimetría de la red fluvial y permite distinguir los tramos activos de forma

20 Coste $(s)=1+(s / \check{s})^{2}$, donde š es la pendiente crítica y s es el valor de la pendiente. 
constante a lo largo del año de aquellos en los que esta circulación es circunstancial.

Ambas redes no coinciden de forma precisa y, sin embargo, es posible asociar la información sobre el caudal de la primera a la localización de la segunda mediante la asignación de los valores de acumulación de flujo a la celdilla más cercana de la red fluvial cartográfica, una vez que ha sido esta transformada a raster. Por otra parte, los valores de flujo acumulado son de una escala mucho mayor que los derivados de la pendiente y, para equipararlos, se ha optado por reducirlos dividiéndolos entre 100, 1.000 y 10.000 , de forma que se han obtenido tres niveles de acumulación diferentes para la red fluvial. La combinación de los tres modelos de pendiente y de los tres modelos de flujo acumulado da lugar a 9 superficies de fricción distintas.

\subsection{La creación de la superficie de costos minimos acumulados $y$ de las rutas óptimas}

A partir de cada una de las superficies de fricción y mediante la herramienta Cost-Distance fue generada una superficie de costo mínimo acumulado en torno a cada uno de los tres destinos: Italica, Ilipa y Naeva. Esta herramienta también da la posibilidad de obtener una segunda capa -Back Link Raster- que indica para cada celdilla cuál es aquella de sus vecinas a la que dirigirse para obtener tal coste. La herramienta Cost Path, finalmente, crea la ruta óptima que une cada origen -Cerro de los Covachos o Loma de los Castillejos- con los destinos anteriores. De este modo, a partir de 2 orígenes y 3 destinos, que pueden ser identificados por la nomenclatura que aparece en la tabla inferior (Fig. 4),

\begin{tabular}{|c|c|c|c|}
\hline & \multicolumn{2}{|c|}{ ORIGEN } \\
\hline & & $\begin{array}{c}\text { CerRo de } \\
\text { LOS Covachos }\end{array}$ & $\begin{array}{c}\text { Loma DE } \\
\text { LOS Castillejos }\end{array}$ \\
\hline \multirow{3}{*}{ Destino } & Italica & 1_1 & $2 \_1$ \\
\hline & Ilipa & 1_2 & $2 \_2$ \\
\hline & Naeva & $1 \_3$ & 2_3 \\
\hline
\end{tabular}

Fig. 4. Origenes y destinos empleados en la generación de ACS $y$ LCP.

Ediciones Universidad de Salamanca / @@@ son generadas 54 rutas óptimas, rutas formadas por celdillas que pueden ser convertidas a líneas con la idea de extraer de ellas la máxima información.

\subsection{Caracterización de rutas óptimas}

Para evaluar la idoneidad de las rutas creadas se ha optado por caracterizarlas con unos criterios que podrían clasificarse en intrínsecos y extrínsecos a ellas. Los primeros se obtienen a partir de la misma ruta y se relacionan con la longitud real, la pendiente media, la longitud de la vía que recorre pendientes superiores al umbral y el tiempo de recorrido; los segundos se derivan de elementos externos a las rutas y se asocian al número y distancia media de asentamientos a menos de $500 \mathrm{~m}$ de ellas, a las intersecciones con las vías pecuarias y caminos antiguos y a los cruces con la red fluvial:

a) La longitud real de las rutas: es calculada a partir del MDE, considerando las diferencias altimétricas en cada tramo; serán más adecuadas las rutas de menor longitud.

b) Pendiente media: obtenida -en valores porcentuales- para cada segmento de arco en función de la relación entre sus diferencias altimétricas y su longitud; serán más idóneas las rutas que posean una menor pendiente media.

c) Longitud de la ruta que pasa por pendientes superiores al umbral especificado (9\%): serían más adecuadas las rutas cuyo trayecto por pendientes superiores al umbral especificado sea inferior, pues las de pequeña longitud pueden ser salvadas más fácilmente mediante zigzag u obras de ingeniería. Se estima que el valor de este criterio es inferior al de la pendiente media debido a que no tiene en cuenta el valor de las pendientes superiores al umbral especificado.

d) El tiempo de recorrido: al no disponer de una función que permita predecir claramente el tiempo que emplearían carros tirados por animales, se estima que puede ser útil conocer cuánto emplearía una persona en recorrerlas, si bien tanto el umbral de pendiente como la velocidad en llano son distintos. Para ello ha sido utilizada la Función de Tobler Modificada (Márquez et 
122 D. Jiménez Madroñal, O. Rodríguez Gutiérrez y J. Márquez Pérez / Transporte del mármol en las canteras...

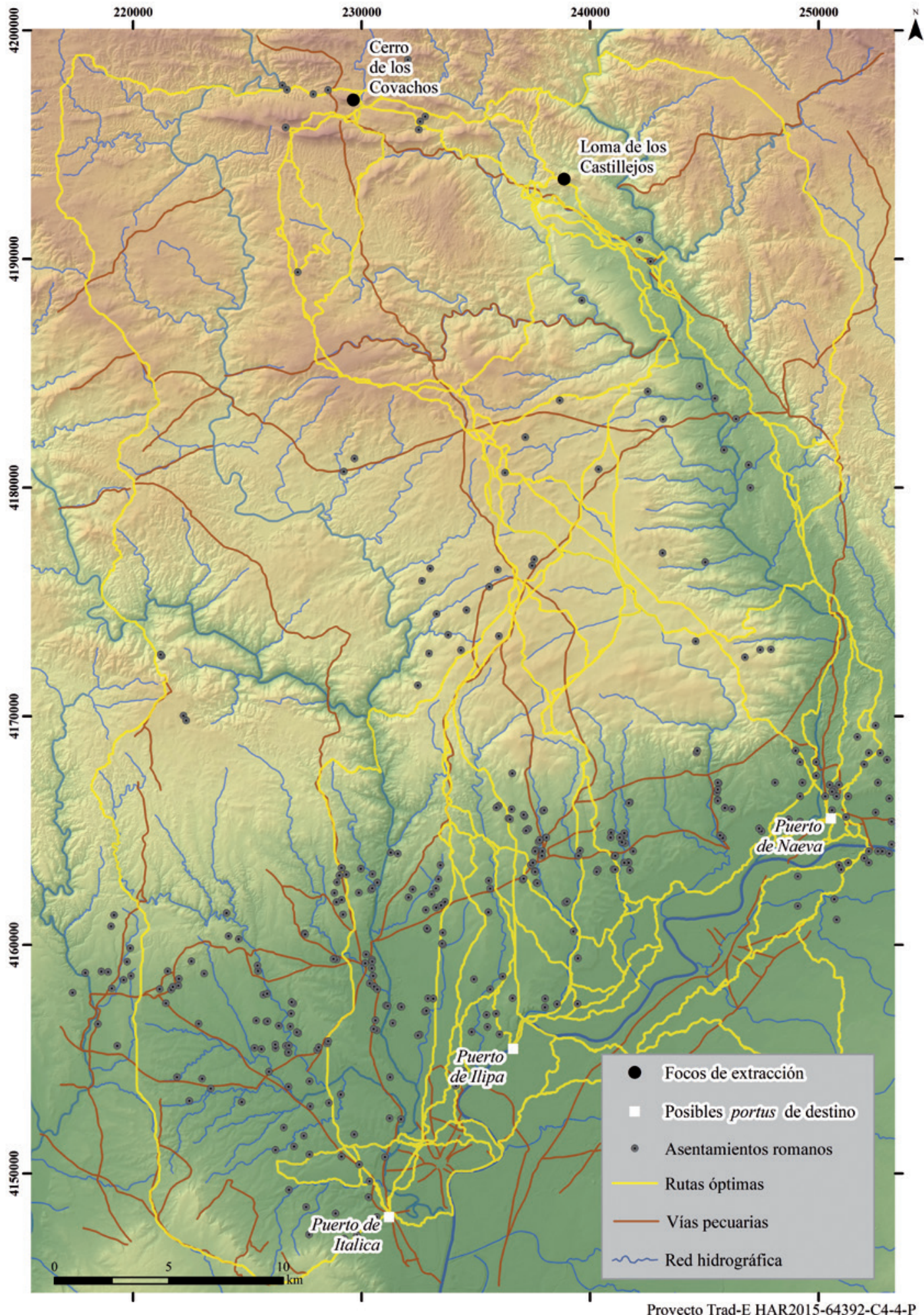

FIG. 5. Rutas óptimas generadas junto con las vías pecuarias existentes y los asentamientos de origen romano. 
al., 2017), que tiene en cuenta la anisotropía del movimiento en función de la pendiente. Se considera que serían más aptas las rutas con menor tiempo de recorrido. El resultado se proporciona en minutos.

e) El número de asentamientos romanos situados a menos de $500 \mathrm{~m}$ de la ruta: se consideran más probables aquellas rutas que posean un mayor número de asentamientos en sus cercanías, en este caso a menos de $500 \mathrm{~m}$, ya que facilita, de haberla, una visibilidad que se considera suficientemente nítida.

f) La distancia media a la que se encuentran los asentamientos de la ruta: este criterio matiza al anterior (e), pues, dado que son múltiples las rutas a caracterizar, se piensa que debe elegirse un límite a partir del cual esta distancia no sea representativa; se valoran como más adecuadas las menores distancias medias.

g) El número de intersecciones de la ruta con la red fluvial: generadas a partir del cruce de los dos elementos lineales, pueden considerarse más convenientes las rutas que presenten menor coincidencia con la red fluvial debido a la dificultad o al coste de atravesarla; sin embargo, es necesaria la existencia de puntos de abastecimiento de agua a lo largo de la ruta, por lo que se trata de un criterio en el que un valor nulo tendría escasa validez.

h) La longitud coincidente con la red de vías pecuarias: dado que es posible que antiguos caminos y veredas se relacionasen con las vías romanas y las hayan perpetuado, tendrían más probabilidad de ser ciertas aquellas en las que la coincidencia con las vías pecuarias fuese mayor. Para evaluar la relación ha sido creado un buffer de igual anchura para cada tipo -cañada: $75 \mathrm{~m}$; cordel: $38 \mathrm{~m}$; vereda: $20 \mathrm{~m}$; y colada: $15 \mathrm{~m}-$, para posteriormente calcular la longitud de ruta que lo atraviese.

Estos criterios han sido seleccionados en función de los datos disponibles, pero, teniendo en cuenta tanto la correlación que puede existir entre algunos como su distinta importancia, se ha procedido a seleccionar cinco de ellos para la validación y posterior comparación de las rutas. Sus nombres y abreviaturas son los siguientes: longitud $3 \mathrm{D}-\mathrm{LONG}-$, pendiente media-PEND-, intersecciones con la red fluvial -Ríos-, número de asentamientos a menos de $500 \mathrm{~m}$-A_NUM-, y longitud coincidente con las vías pecuarias -VVPP-. El tiempo de recorrido -MIN-, la longitud de ruta que discurre por pendientes superiores al 9\% -LONP9- y la distancia media a los asentamientos cercanos -A_DIs- son empleados únicamente como medio de completar la información que aportan los anteriores.

\subsection{El proceso de validación y comparación de las rutas}

Para validar y comparar las distintas rutas a partir de los criterios previamente seleccionados se ha llevado a cabo un proceso en dos fases: a) la normalización de sus valores -en una escala de 1 a 100 y en función de los valores del conjunto que les corresponda-, disponiéndolos en igual sentido de modo que el valor más alto pueda considerarse como propio de la ruta más adecuada; b) la ponderación de las variables, que se lleva a cabo mediante el Proceso Analítico Jerárquico desarrollado por Saaty (1980): basado en la comparación por pares de los criterios seleccionados, el resultado dota de racionalidad y consistencia al resultado final. La suma de las variables así ponderadas permite caracterizar con un solo valor cada una de las rutas (Fig. 6).

\begin{tabular}{|l|c|c|c|c|c|}
\hline & LONG. & PEND. & RíOS & VVPP & A_NUM \\
\hline LONG. & 1 & 1,1 & 4 & 6 & 7 \\
\hline PEND. & $1 / 1,1$ & 1 & 3,5 & 5 & 6 \\
\hline RíOS & $1 / 4$ & $1 / 3,5$ & 1 & 2 & 5 \\
\hline VVPP & $1 / 6$ & $1 / 5$ & $1 / 2$ & 1 & 1,5 \\
\hline A_NUM & $1 / 7$ & $1 / 6$ & $1 / 3$ & $1 / 15$ & 1 \\
\hline Ponderación & 0,41 & 0,35 & 0,12 & 0,07 & 0,05 \\
\hline
\end{tabular}

FIG. 6. Variables empleadas como caracterizadores de la verosimilitud de las rutas y resultados de la ponderación. 


\begin{tabular}{|l|c|c|c|c|c|c|c|c|c|c|c|}
\hline \multicolumn{1}{|c|}{ ORIGen } & DESTINO & Código & LONG. & PEND. & Ríos & VVPP & A_NUM & MIN & LONP 9 & A_DIS & VALOR \\
\hline $\begin{array}{l}\text { Cerro de los } \\
\text { Covachos }\end{array}$ & Naeva & C_1_3 & 49.533 & 3,2 & 3 & 1.174 & 23 & 737 & 3.862 & 279 & 71,5 \\
\hline $\begin{array}{l}\text { Loma de los } \\
\text { Castillejos }\end{array}$ & Naeva & C_2_3 & 36.450 & 3,01 & 4 & 3.517 & 17 & 569 & 2.153 & 158 & 80,32 \\
\hline
\end{tabular}

FIG. 7. Rutas que alcanzan mayor valoración entre los dos orígenes y el destino óptimo.

\subsection{Creación de un corredor entre orígenes y destinos}

Para completar el análisis y a partir de la superficie de coste que ha proporcionado mejores resultados -H_R10000, C-, se ha generado lo que se denomina un corredor mediante el cálculo de las superficies de costo mínimo acumulado entre todos los orígenes y todos los destinos en ambos sentidos, y calculando posteriormente su promedio. Esto posibilita obtener un resultado con valores superficiales continuos que complementa a los anteriores, y que para algunos autores como Howey (2011) o Murrieta-Flores (2012) es posiblemente una manera más realista de predecir patrones de antiguos desplazamientos.

\section{Resultados}

\subsection{Rutas con igual origen y destino óptimo}

Son comparadas entre sí las rutas que parten del Cerro de los Covachos y de la Loma de los Castillejos hacia el destino, de los tres analizados, que pueden alcanzar con un menor coste. Naeva se muestra, para ambos orígenes, como el destino al que llevarían las rutas óptimas con un mayor valor en la ponderación. Italica e Ilipa quedarían, en este sentido, descartadas (Figs. 7 y 8 ).

\subsection{Rutas con igual origen y destino}

Se trata de una comparación entre rutas que parten del mismo punto y se dirigen al mismo destino. De las 9 rutas generadas en cada una de las seis combinaciones entre orígenes y destinos, interesa conocer cuál es la óptima. A destacar la puntuación alcanzada por la ruta que une el Cerro de los Covachos con Italica -C_1_1- y la de la que enlaza la Loma de los Castillejos con Naeva-C_2_3-(Figs. 9 y 10).

\subsection{Rutas con diferente origen e igual destino}

Se analiza la posibilidad de que un solo puerto fuese el destino de los materiales extraídos de las canteras; en este caso, un tanto diferente a los anteriores, es la longitud el factor principal a considerar, si bien desde dos puntos de vista diferentes: el coste de su construcción y la longitud que debe recorrerse desde cada punto inicial. Desde esta óptica dos son las principales alternativas: por un lado, que las dos rutas se unan en algún punto de su recorrido, compartiéndolo parcialmente -mayor coste económico en su construcción y mantenimiento, pero inferior tiempo total de recorrido-, y, por otro, que una ruta parta de un origen y se dirija al segundo, para posteriormente compartir la totalidad del restante trayecto -supone un menor coste económico a costa de una mayor inversión en tiempo-. En ambos casos, dado el escaso número de rutas comparadas, el proceso de estandarización y ponderación puede no reflejar las diferencias reales, y de ahí que probablemente interese más prestar atención a los valores alcanzados en cada criterio.

\subsubsection{Rutas con recorrido común}

Si las rutas comparten parcialmente el recorrido, puede observarse que las que se dirigen a Naeva tienen una longitud bastante inferior, cruzan la red fluvial en menos ocasiones y tienen en sus cercanías más asentamientos. Por su parte, las que se dirigen a Ilipa e Italica, aunque su pendiente media es ligeramente inferior y coinciden en una mayor longitud 


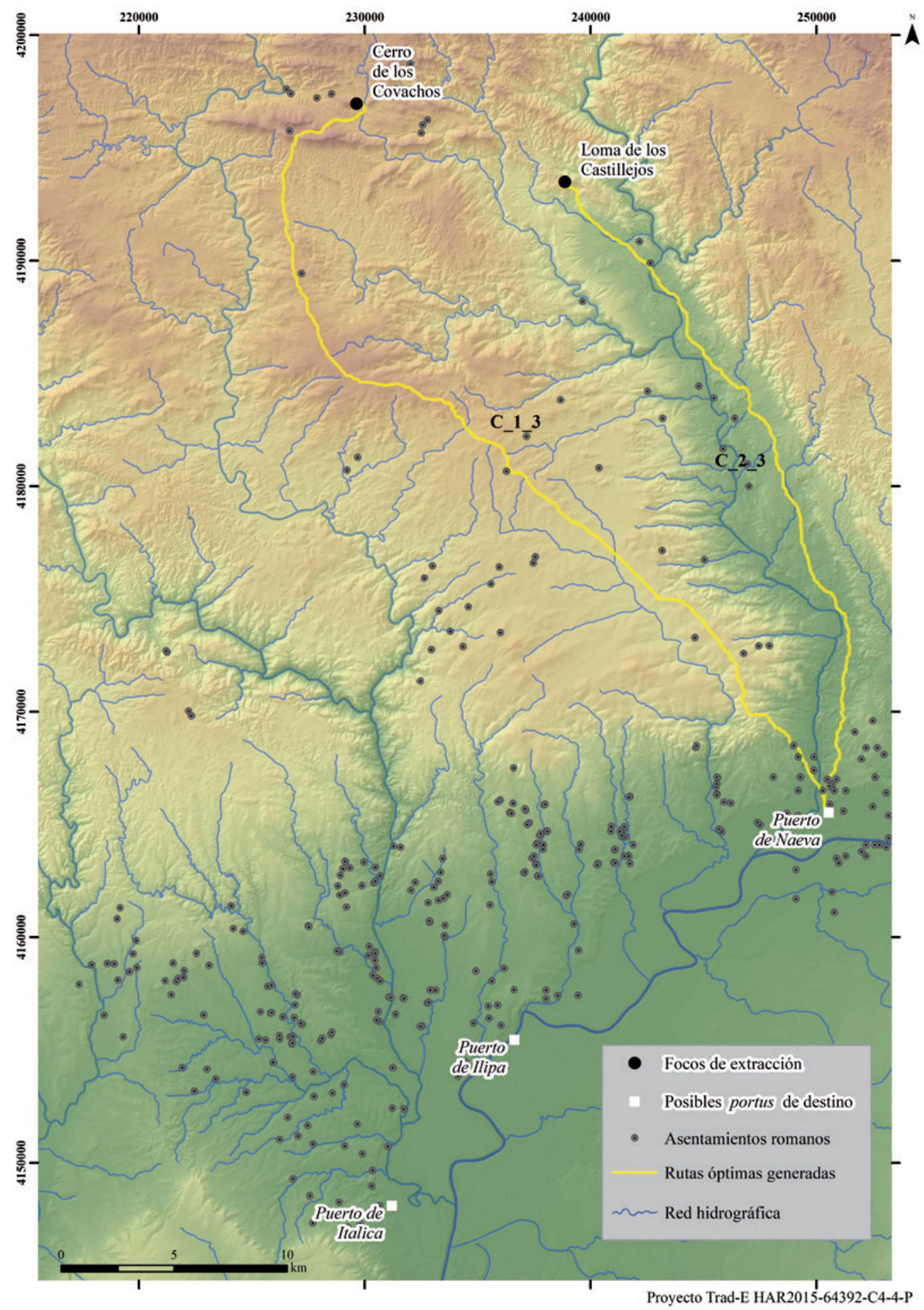

Fig. 8. Localización de las rutas óptimas que alcanzan mayor valoración entre los dos orígenes y el más adecuado destino para cada uno. 


\begin{tabular}{|c|c|c|c|c|c|c|c|c|c|c|c|}
\hline ORIGEN & DESTINO & CóDIGO & LONG. & PEND. & Ríos & VVPP & A_NUM & MIN & LONP9 & A_DIS & VALOR \\
\hline Cerro de los Covachos & \multirow{2}{*}{ Italica } & C_1_1 & 62.081 & 2,58 & 3 & 3.660 & 13 & 908 & 2.390 & 235 & 82,03 \\
\hline Loma de los Castillejos & & C_2__1 & 54.768 & 3,08 & 7 & 5.128 & 13 & 856 & 4.302 & 235 & 66,54 \\
\hline Cerro de los Covachos & \multirow{2}{*}{ Ilipa } & C_1_2 & 54.812 & 2,84 & 3 & 1.207 & 11 & 803 & 2.465 & 240 & 70,51 \\
\hline Loma de los Castillejos & & C_2_2 & 48.070 & 3,16 & 6 & 805 & 9 & 756 & 4.266 & 203 & 63,29 \\
\hline Cerro de los Covachos & \multirow{2}{*}{ Naeva } & C_1_3 & 49.533 & 3,42 & 3 & 1.174 & 23 & 737 & 3.862 & 279 & 65,54 \\
\hline Loma de los Castillejos & & C_2_3 & 36.450 & 3,01 & 4 & 3.517 & 17 & 569 & 2.153 & 158 & 80,30 \\
\hline
\end{tabular}

Fig. 9. Valor alcanzado por las rutas óptimas que alcanzan mayor valoración, entre los dos orígenes y los tres destinos propuestos.
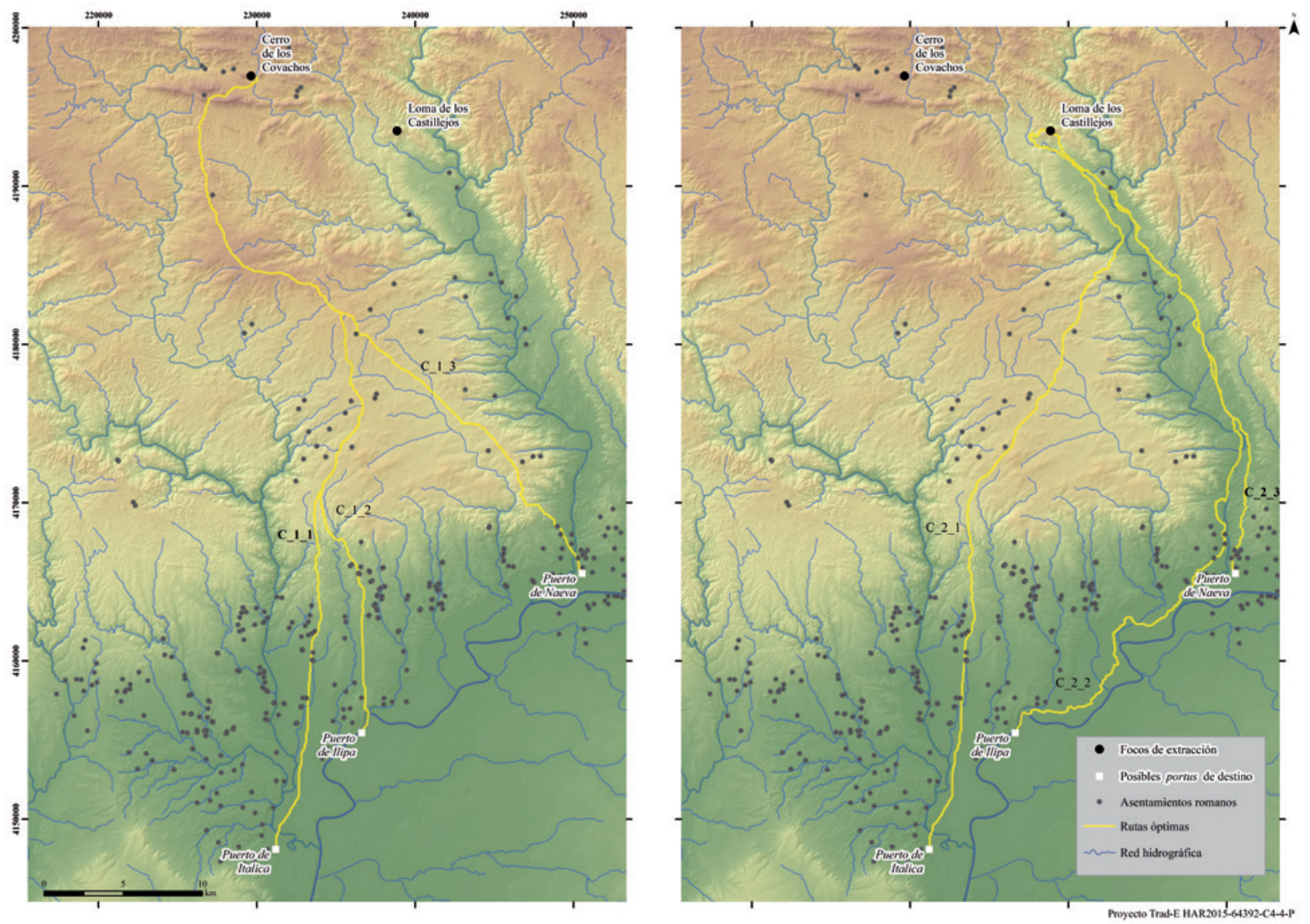

Fig. 10. Localización de las rutas óptimas que alcanzan mayor valoración, entre los dos orígenes y los tres destinos propuestos.

con las vías pecuarias, suponen un recorrido de longitud muy superior (Figs. 11 y 12).

\subsubsection{Rutas que unen los dos orígenes}

Si las rutas comparten totalmente el recorrido, a pesar de que Naeva es el destino al que se dirige la ruta con menor longitud, y que el número de asentamientos en sus cercanías es superior a las otras dos alternativas, tras el proceso de estandarización y ponderación es la ruta que se dirige a Italica la que alcanza un mayor valor, debido tanto a su menor pendiente media como a poseer valores intermedios en los restantes criterios. Como se indicó 
anteriormente, habría que tomar este resultado con precaución (Figs. 13 y 14).

\subsection{Rutas propuestas por los investigadores vs. rutas óptimas}

En relación con las rutas propuestas por los investigadores, la de Sillières -Cerro de los Covachos-Italica- tiene una valoración muy próxima a la más adecuada de las rutas óptimas con igual origen y destino $-82,03$ vs. 80,93, respectivamente-: se trata de una ruta de menor longitud real que la
C_1_1, a costa de atravesar una mayor longitud de pendientes superiores al umbral del 9\%, e intersecar en muchas más ocasiones la red fluvial; a su favor, el porcentaje de longitud coincidente con vías pecuarias -superior al 30\%-.

La ruta propuesta por Corzo y Toscano, uniendo el Cerro de los Covachos con Italica, tiene un valor muy inferior a los anteriores -40,01-: a una mayor longitud se ańade atravesar pendientes bastante más abruptas, tener un gran número de intersecciones con la red fluvial y poseer una menor coincidencia con las vías pecuarias actuales. Tan solo es destacable el número de asentamientos en sus inmediaciones.

\begin{tabular}{|c|c|c|c|c|c|c|c|c|c|c|}
\hline ORIGEN & DESTINO & LONG. & PEND. & Ríos & vVPp & A_NUM & MIN & LONP9 & A_DIS & VALOR \\
\hline Cerro de los Covachos & \multirow{2}{*}{ Italica } & \multirow{2}{*}{91.274} & \multirow{2}{*}{3,05} & \multirow{2}{*}{8} & \multirow{2}{*}{5.845} & \multirow{2}{*}{16} & \multirow{2}{*}{1.764} & \multirow{2}{*}{5.898} & \multirow{2}{*}{234} & \multirow{2}{*}{42} \\
\hline Loma de los Castillejos & & & & & & & & & & \\
\hline Cerro de los Covachos & \multirow{2}{*}{ Ilipa } & \multirow{2}{*}{85.158} & \multirow{2}{*}{3,24} & \multirow{2}{*}{8} & \multirow{2}{*}{3.625} & \multirow{2}{*}{16} & \multirow{2}{*}{1.402} & \multirow{2}{*}{6.709} & \multirow{2}{*}{223} & \multirow{2}{*}{38,05} \\
\hline Loma de los Castillejos & & & & & & & & & & \\
\hline Cerro de los Covachos & \multirow{2}{*}{ Naeva } & \multirow{2}{*}{66.256} & \multirow{2}{*}{3,69} & \multirow{2}{*}{6} & \multirow{2}{*}{1.508} & \multirow{2}{*}{23} & \multirow{2}{*}{1.252} & \multirow{2}{*}{6.027} & \multirow{2}{*}{192} & \multirow{2}{*}{58} \\
\hline Loma de los Castillejos & & & & & & & & & & \\
\hline
\end{tabular}

FIG. 11. Comparación entre las características de las rutas óptimas -con coincidencia parcial- que alcanzan mayor valoración, entre los dos origenes y cada uno de los tres destinos.
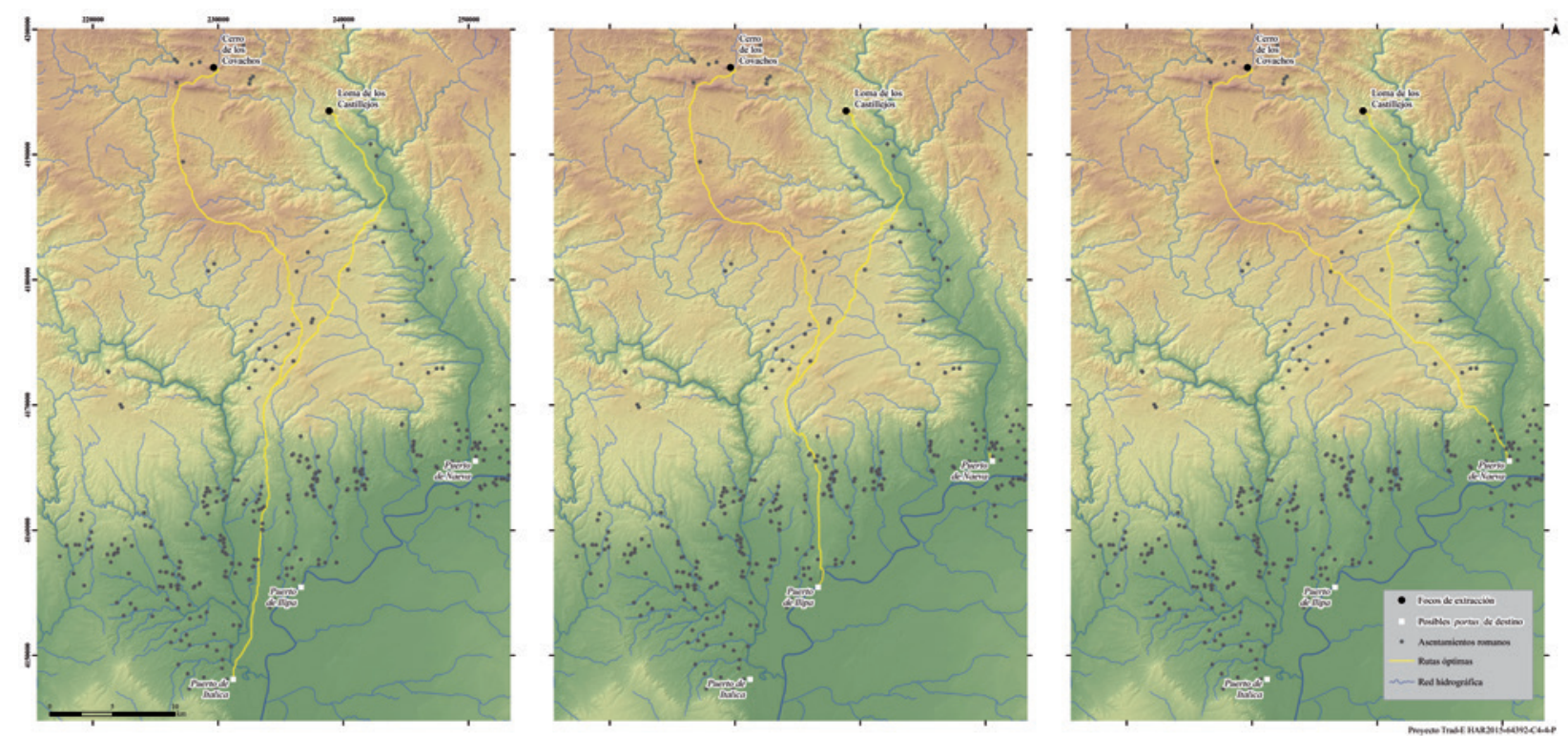

FIG. 12. Localización de las rutas óptimas -con coincidencia parcial- que alcanzan mayor valoración, entre los dos orígenes y cada uno de los tres destinos. 


\begin{tabular}{|l|c|c|c|c|c|c|c|c|c|}
\hline & LONG. & PEND. & RÍOS & VVPP & A_NUM & MIN & LONP9 & A_DIS & VALOR \\
\hline $\begin{array}{l}\text { Loma de los Castillejos/ } \\
\text { Cerro de los Covachos/ } \\
\text { Italica }\end{array}$ & 74.019 & 3,12 & 6 & 4.901 & 17 & 1.027 & 5.767 & 226 & 55,67 \\
\hline $\begin{array}{l}\text { Loma de los Castillejos/ } \\
\text { Cerro de los Covachos / } \\
\text { Ilipa }\end{array}$ & 66.750 & 3,40 & 6 & 2.448 & 15 & 995 & 6.141 & 230 & 43,56 \\
\hline $\begin{array}{l}\text { Cerro de los Covachos/ } \\
\text { Loma de los Castillejos/ } \\
\text { Naeva }\end{array}$ & 48.907 & 3,76 & 7 & 4.801 & 21 & 777 & 5.976 & 164 & 52,71 \\
\hline
\end{tabular}

FIG. 13. Comparación entre las características de las rutas óptimas -con coincidencia total- que alcanzan mayor valoración, entre los dos orígenes y cada uno de los tres destinos.
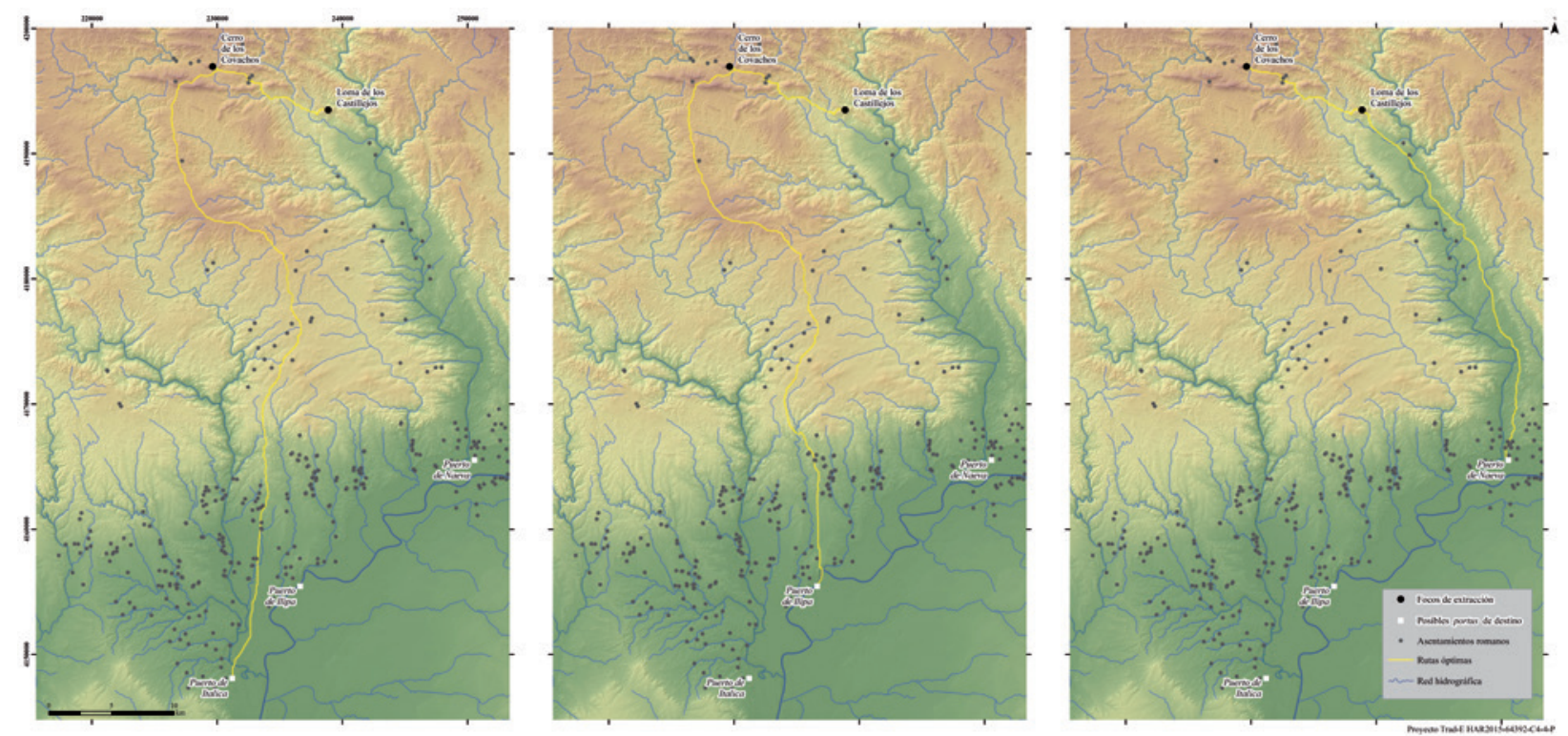

FIG. 14. Localización de las rutas óptimas -con coincidencia total-que alcanzan mayor valoración, entre los dos orígenes y cada uno de los tres destinos.

La ruta propuesta por Corzo y Toscano en la zona oriental -Cerro de los Covachos-Naevatampoco es comparable con la ruta óptima que alcanza mayor valor en ese ámbito -C_1_3-: si bien posee una menor longitud, pasa por pendientes muy superiores, dobla el número de ocasiones en que intersecta a la red fluvial y, a pesar de coincidir en una mayor longitud con las vías pecuarias, el número de asentamientos a menos de $500 \mathrm{~m}$ es muy inferior (Figs. 15 y 16).

\subsection{Creación de un corredor entre todos los orígenes $y$ destinos}

La generación de una superficie en la que cada celdilla contiene el promedio del coste mínimo acumulado para acceder tanto a la cantera como al puerto que le supone un menor coste, da la posibilidad de observar que para la Loma de los Castillejos es claramente Naeva el destino apropiado, mientras que para el Cerro de los Covachos también podría 
ser Ilipa, quedando Italica en un segundo término (Fig. 17).

\section{Discusión}

El debate acerca del proceso metodológico seguido en este trabajo y de la validez de los resultados obtenidos se centra en algunos puntos claramente interrelacionados: la evolución del paisaje y, en concreto, de su altimetría; la creación de la superficie de fricción y las unidades en que medirla; la resolución espacial de los datos, especialmente del modelo digital de elevaciones; la elección del software y algoritmo de cálculo de ACS y LCP; y la adecuación de estos algoritmos a la predicción sobre la localización de vías de comunicación antiguas.

Las rutas óptimas generadas sobre datos actuales se desvían quizá de las originales, debido a los cambios en el paisaje. En este sentido, reconstruir al menos su altimetría a partir de cartografía antigua es difícil debido a su relativamente limitada información y precisión, y a los efectos derivados de la aplicación de métodos de interpolación a curvas de nivel y cotas altimétricas para generar superficies continuas (Verhagen et al., 2019). De hecho, autores como Herzog (2013a) indican que el MDE disponible difícilmente representará la altimetría existente en el momento de crear rutas ancestrales, pues muchos yacimientos pueden encontrarse hasta $5 \mathrm{~m}$ bajo sedimentos derivados de los procesos de erosión. Sin embargo, la resolución espacial de los datos altimétricos es esencial para el cálculo de la pendiente (Jobe y White, 2009; Pingel, 2010; Kay, 2012, etc.): a medida que aumenta el tamaño de celdilla disminuye su valor, de modo que puede llegar a oscurecer escarpes y pequeńos acantilados de una extensión horizontal limitada (Lock y Pouncet, 2010). Por esta razón, el MDE elegido en este trabajo puede considerarse solo relativamente adecuado, pues si bien no posee una gran resolución espacial -autores como Herzog y Posluschny (2011) indican que como máximo debería ser igual al paso de una persona, $60 \mathrm{~cm}$, mientras que aquí se emplea el de $10 \mathrm{~m}$ - sí refleja la topografía de un espacio que ha sufrido una gran transformación en los últimos tiempos, el embalse de Melonares.

Respecto a la generación de la superficie de fricción, y en concreto la integración de los factores susceptibles de retardar el movimiento, va en paralelo a la decisión acerca del tipo de unidad en que se considera conveniente representarla.

Existen diferentes algoritmos para el cálculo de la pendiente, si bien la mayoría de ellos se centran en obtener en cada celdilla una media a partir de las diferencias altimétricas entre las celdillas que rodean (Verhagen et al., 2019), otros integran directamente las diferencias altimétricas en relación con la distancia, consiguiendo así obtener la pendiente en la dirección del movimiento, la pendiente efectiva. A esto habría que añadir la dificultad que representa la existencia de un umbral de pendiente: salvando obras de ingeniería -túneles o puentes-, la cuestión solo puede resolverse disminuyendo el gradiente mediante un incremento en la longitud de la ruta ya sea buscando zonas más aptas, o a través de

\begin{tabular}{|l|l|c|c|c|c|c|c|c|c|c|}
\hline $\begin{array}{c}\text { ORIGEN/ } \\
\text { DESTINO }\end{array}$ & \multicolumn{1}{|c|}{ CÓDIGO } & LONG. & PEND. & Ríos & VVPP & A_NUM & MIN & LONP9 & A_DIS & VALOR \\
\hline \multirow{2}{*}{$\begin{array}{l}\text { Cerro de los } \\
\text { Covachos/ } \\
\text { Italica }\end{array}$} & C_1_1 & 62.081 & 2,58 & 3 & 3.600 & 13 & 908 & 2.390 & 235 & 82,03 \\
\cline { 2 - 11 } & Sillières & 58.843 & 3,43 & 9 & 18.456 & 14 & 898 & 13.465 & 258 & 80,93 \\
\cline { 2 - 11 } & $\begin{array}{l}\text { Corzo-Toscano } \\
\text { (occ.) }\end{array}$ & 63.643 & 8,03 & 16 & 2.418 & 20 & 1.106 & 29.057 & 239 & 40,01 \\
\hline $\begin{array}{l}\text { Cerro de los } \\
\text { Covachos/ } \\
\text { Naeva }\end{array}$ & C_1_3 & 49.533 & 3,42 & 3 & 1.174 & 23 & 737 & 3.852 & 280 & 65,54 \\
\cline { 2 - 11 } & $\begin{array}{l}\text { Corzo-Toscano } \\
\text { (or.) }\end{array}$ & 46.084 & 5,02 & 7 & 3.960 & 11 & 734 & 15.040 & 271 & 46,95 \\
\hline
\end{tabular}

FIG. 15. Comparación de las características entre las rutas óptimas que alcanzan mayor valoración y las rutas propuestas por los investigadores. 


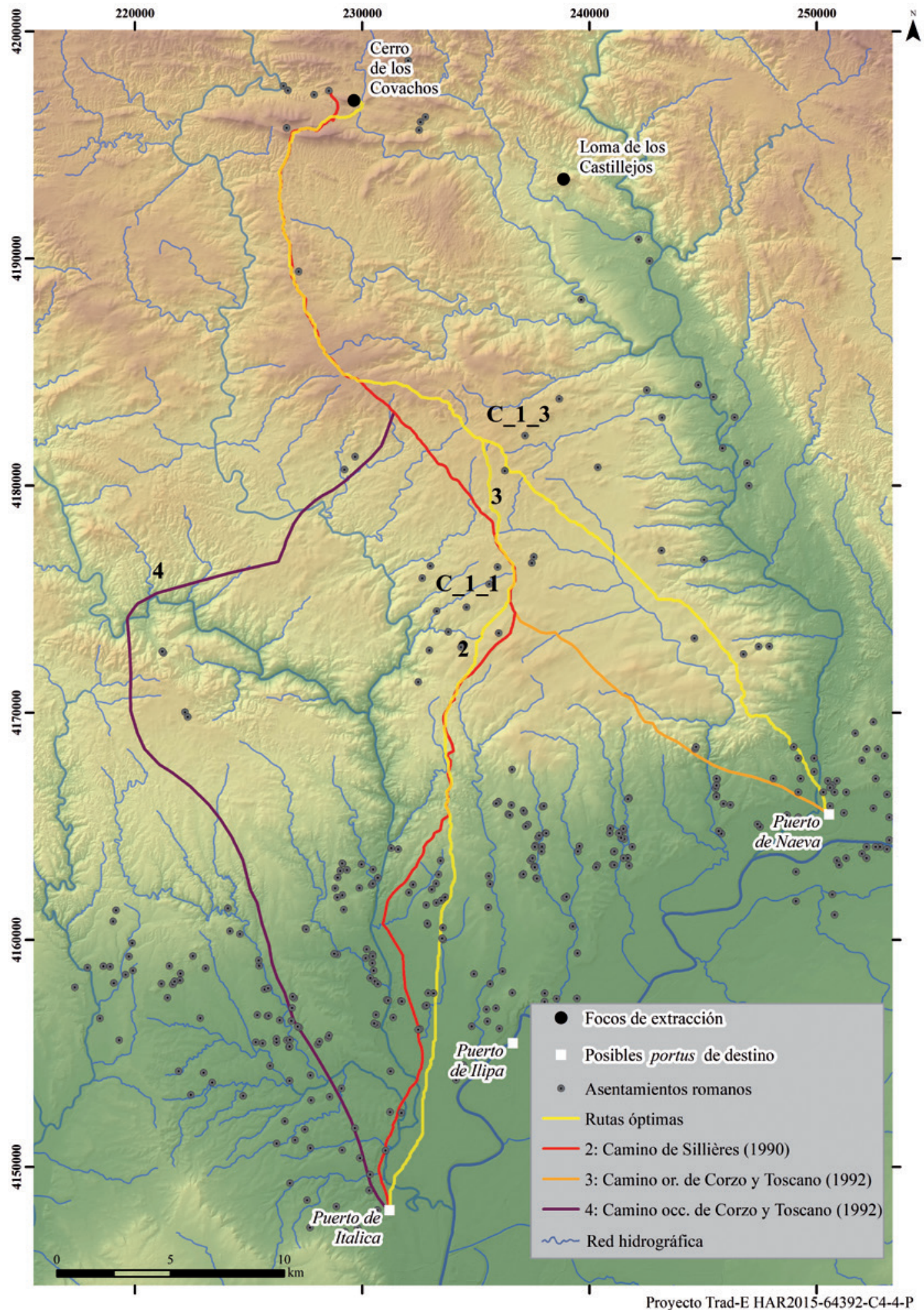

FIG. 16. Localización de las rutas propuestas junto a las rutas óptimas que alcanzan mayor valoración. 


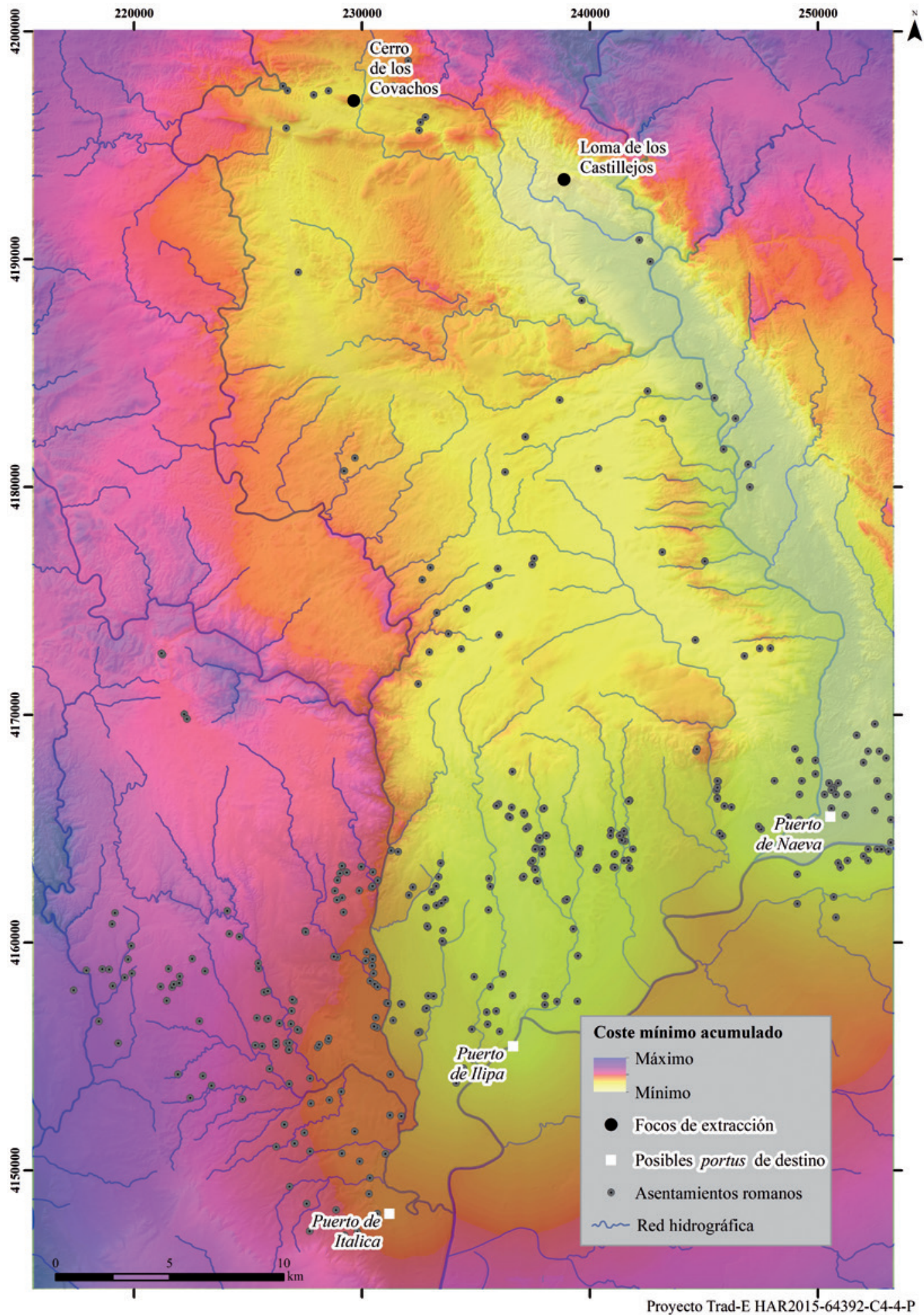

FIG. 17. Corredor generado a partir del promedio de superficies de costos minimos acumulados, generadas en torno a la combinación de origenes y destinos con mayor valoración. 
zigzag (Kay, 2012), lo que requiere un tamaño de celdilla adecuado para representarlo (Llobera y Sluckin, 2007). Dado que no es posible considerar el umbral especificado (9\%) como un límite nítido en zonas de cierto relieve como la aquí presentada, se opta por aumentar su fricción incrementando su valor de forma lineal o exponencial. De todas formas, es necesario reconocer que ni el tamaño de celdilla empleado es el más adecuado, ni la pendiente que el algoritmo de ACs encuentra está calculada en función de la dirección del movimiento.

La red fluvial es considerada otro importante factor de fricción (Jobe y White, 2009; Herzog, 2013a), cuando no una barrera al movimiento, y existen distintos métodos para integrar sus valores ya sea incrementando directamente el valor de pendiente coincidente, hacerlo también en sus cercanías $^{21}$ (Fiz y Orengo, 2008; Herzog, 2013a), o considerando el gasto energético que supone atravesarla (Wheatley et al., 2010). Aquí se ha optado por caracterizar cada celdilla coincidente con la red fluvial por el tamańo de su cuenca vertiente, sumando ese valor al de su propia pendiente tras haberlo previamente rebajado en distintas proporciones para adecuarlo a su escala.

A pesar de que estudios previos han considerado el tipo de terreno (Soule y Goldman, 1972; Pandolf et al., 1977) especialmente importante cuando la pendiente es crítica, aquí no ha sido tenido en cuenta debido a la uniforme distribución de la litología: rocas duras -volcánicas, pizarras, esquistos o calizas metamórficas- en toda la zona no coincidente con la cuenca del Viar -conglomerados, arenas y calizas- o del Guadalquivir -arenas, limos y arcillas-.

Por otra parte, la función que calcula la fricción es más importante que el número de vecinos examinados por el algoritmo de coste, la calidad de los

21 Van Leusen, M.: Pattern to process: methodological investigations into the formation and interpretation of spatial patterns in archaeological landscapes. Tesis doctoral inédita presentada en 2002 en la Rijkuniversiteit Groningen (https://www.researchgate.net/publication/30480196_ Pattern_to_process_methodological_investigations_into_ the_formation_and_interpretation_of_spatial_patterns_ in_archaeological_landscapes/link/). datos altimétricos o el modo de resolver la anisotropía de la pendiente (Herzog, 2013a). Y las unidades en las que se mide ese coste son claves: si la pendiente es el principal factor a tener en cuenta en el desplazamiento animal terrestre, $\mathrm{y}$ tiempo y gasto energético son las formas usuales de medir su coste, hay que considerar que el valor de la pendiente no es equiparable al de atravesarla, del mismo modo que una pendiente de $2^{\circ}$ no supone el doble de coste que atravesar una pendiente de $1^{\circ}$ (Pingel, 2010).

En lo que se refiere a las unidades en que se mide la fricción, emplear las de tiempo parece más relacionado con tipos de movimientos en los que la rapidez es fundamental -por ejemplo, el desplazamiento de tropas-, mientras que utilizar unidades de energía puede relacionarse más con el transporte de materiales pesados mediante bestias de carga. De hecho, Herzog (2010) prefiere este tipo de funciones a las anteriores cuando se trata de predecir rutas antiguas, debido a que los fisiólogos son expertos en medir el gasto energético en humanos y animales. Por otra parte, esta autora, al comparar (2013b) diferentes funciones para el cálculo del coste a partir de los resultados obtenidos por Minetti et al. (2002), concluye que el polinomio de $6^{\circ}$ es el que mejor se aproxima a datos experimentales, mientras que la ecuación desarrollada por Llobera y Sluckin (2007) es la que más se ajusta a los empíricos, empleando ambas unidades de energía. Sin embargo, las unidades de tiempo son más fáciles de entender y comparar, a pesar de que ni unas ni otras están disponibles para medir el coste derivado del empleo de carros o animales cargados, debido a la falta de datos experimentales (Herzog, 2013b), con la ya citada excepción de Raepsaet (2002).

En este trabajo no se han empleado unidades de tiempo ni de energía, sino de pendiente. Esta decisión viene dada por la necesidad de integrar tanto un umbral de pendiente adecuado al transporte mediante carros, como el asociado a atravesar la red fluvial con estos vehículos, dado que ambos incrementos hubieran alterado la función de cálculo de coste medido en tiempo o energía, específicamente diseñadas -velocidad máxima y umbral de pendiente- para el movimiento pedestre. 
Otro tema de debate es el software a utilizar; Gietl et al. (2008) compararon las rutas óptimas generadas con tres conocidos programas -Idrisi, ArcGIS y Grass-, indicando que no fue posible obtener resultados ni siquiera similares en algunas zonas. La mayoría de los programas emplean el algoritmo de Dijkstra (1959), a pesar de que genera rutas que suponen un menor tiempo a costa de un mayor coste metabólico, elige una sola solución cuando encuentra dos celdillas con igual coste mínimo (Rees, 2004) o supone mejoras en tiempo de computación como la que presenta el $A^{*}$ algorythm (Herzog, 2013b). La utilización del algoritmo de ACs entre los programas difiere respecto al número de celdillas investigado en cada caso -ArcGis solo examina las 8 vecinas a la central mientras que Grass permite aumentar a 16-y, especialmente, respecto al tratamiento de la anisotropía de la pendiente: si el coste depende de la dirección en que es afrontada la pendiente, por cada celdilla debería conocerse la pendiente en cada una de sus 8 direcciones básicas. Este problema tratan de resolverlo de distinta forma, aunque tal y como Herzog indica (2013a), o no han sido implementados correctamente los métodos, o no aportan suficiente documentación para juzgar sus resultados. Arcgis dispone de la herramienta PathDistance para realizar esta labor y, sin embargo, la interpretación de su utilización es compleja a pesar de que Tripcevich (2009) generó una tabla de factor vertical basada en la función de Tobler con este fin. Grass parece, en definitiva, el software más robusto (Bevan, 2011), ya que calcula las pendientes directamente de las diferencias altimétricas en el MDE, analiza 16 celdillas en lugar de 8 -estrategia del caballo de ajedrez- y proporciona los resultados en valores de tiempo. Sin embargo, el algoritmo que calcula el coste anisotrópico está basado en el de Langmuir (2004) y, por tanto, está adaptado al modo de afrontar la pendiente por parte de personas. Por esta razón aquí se optó por emplear ArcGIS y su algoritmo CostDistance que, a pesar de ser isotrópico, proporcionaba resultados más fáciles de entender. Dado que las vías romanas eran utilizadas en ambos sentidos, y que la diferencia altimétrica entre canteras y puertos no superaba los 450 metros

Ediciones Universidad de Salamanca / ㅇతఠ en los más de $40 \mathrm{~km}$ que los separan -pendiente del $1 \%$ - no interesó tanto la anisotropía de la pendiente como calcular, una vez establecida la ruta óptima, el tiempo que podía tardar en recorrerse en ambos sentidos, considerando, ahora sí, la anisotropía; para ello fue empleada la función Modified Hiking Function (Márquez et al., 2017).

Por último, hay que distinguir entre path y route: path puede traducirse por camino muy utilizado y hasta pavimentado, mientras que el término route se asociaría más al espacio por el que se desplaza quien trata de tomar la dirección que le supone menor esfuerzo (Pingel, 2010). Independientemente del algoritmo de coste utilizado, las funciones de ACS y LCP generan rutas que para el caminante suponen un menor tiempo o esfuerzo para ir de un punto a otro. Sin embargo, los antiguos caminos prefieren las crestas a los valles, y si estas tienen muchos desniveles se prefiere ir a un nivel más bajo, pero no siguiendo las curvas de nivel porque requieren mucha construcción (Herzog, 2013a). Cuando se trata de predecir la localización de vías consolidadas por su uso en la antigüedad, parece más lógico centrarse en los path que en las routes y, por tanto, en encontrar aquellas zonas por las que, con un mayor coste temporal, pudieran haber sido trazadas vías que posibilitasen un menor gasto económico -en términos de construcción y mantenimiento- y facilitando así el tránsito de carros y bueyes. Aquí cobra sentido la afirmación de Verhagen et al. (2019) acerca de que el término "óptima" debería relativizarse, y los resultados derivados del proceso de creación de rutas óptimas deberían ser considerados como una hipótesis más. La creación de corredores entre los puntos de origen y destino, al no definir claramente líneas sino zonas difusas, podría predecir de forma más realista los patrones de desplazamiento antiguos (e.g. Howey, 2011; Murrieta-Flores, 2012).

\section{Conclusiones}

Cuando se trata de emplear datos del presente para tratar de predecir la localización de elementos constructivos del pasado, tener alguna certeza acerca 
de los resultados puede depender tanto de cómo se acomoden estos a los vestigios que resten de ese pasado como a una lógica basada en la eficiencia que se le supone a tales construcciones. Quizá sea esta una de las razones por las que la problemática asociada a la reconstrucción de itinerarios antiguos, y en concreto a la localización de vías romanas desaparecidas, sea tan profusa y variada $y$, al mismo tiempo, una materia de investigación tan atractiva.

Los resultados descritos, basados en la generación de 54 rutas óptimas y su posterior ponderación, llevan a una serie de conclusiones respecto a las rutas que pudieron conectar las canteras de Almadén de la Plata -Cerro de los Covachos y Loma de los Castillejos- con los puntos de recepción del material -Italica, Ilipa y Naeva-:

- Si se enlaza cada origen con el destino que puede alcanzar de forma más favorable, de las 54 rutas óptimas generadas dos poseen un valor muy superior a las restantes: la que une el Cerro de los Covachos con Italica-C_1_1- y la que enlaza la Loma de los Castillejos con Naeva-C_2_3-.

- Si es necesario seleccionar un solo destino para ambos puntos de origen, yendo por rutas diferentes, Naeva sería el lugar seleccionado.

- En el caso de que se elija un solo destino, esta vez para rutas que compartan de forma total o parcialmente el recorrido, podrían ser tanto Italica como Naeva los puntos hacia los que se dirigiría la ruta que alcanza mayor valoración.

- La ruta propuesta por Sillières, que enlaza el Cerro de los Covachos con Italica, alcanza una puntuación similar a la C_1_1, por lo que podría considerarse mucho más probable que las otras dos rutas propuestas por Corzo y Toscano.

En cualquier caso, es preciso hacer notar que a partir de la revisión de los asentamientos rurales romanos situados en el curso medio del Viar (Fernández Flores y Carrasco, 2013-2014) se identifican al menos cinco yacimientos en la que podría definirse como el área de influencia de la ruta, definida con fin en Naeva. En ellos cabría quizá esperar el uso de materiales marmóreos que permitiera evidenciar el paso por estos puntos, entendiéndolos como nodos

Ediciones Universidad de Salamanca / ㅇతఠ en el trazado de la ruta pero, lamentablemente, ni siquiera constan en las pequeñas termas del yacimiento conocido como La Tetilla. Es preciso tener en cuenta el arrasamiento y expolio generalizados sufridos por las estructuras y acabados en estos yacimientos rurales, unido al hecho de que el testimonio ex silentio no debe llevar a conclusiones apriorísticas.

Respecto a la metodología utilizada en este trabajo, existen numerosos condicionantes no fácilmente parametrizables que no han sido considerados en un estudio de este tipo: factores naturales y culturales que condicionan la movilidad no fueron incluidos, lo que ha de ser tenido en cuenta para la interpretación de los datos. Sin embargo, a partir de los resultados obtenidos sí es posible conocer cuáles pudieron ser los caminos más viables en términos de coste hasta los tres posibles núcleos receptores ubicados en el valle del Guadalquivir, y entre ellos, que aquel que une las canteras de Almadén de la Plata con la antigua Naeva es la opción más favorable.

También quedan fuera de nuestro actual conocimiento, lamentablemente, los datos relativos a la gestión de las canteras de Almadén de la Plata y sus materiales, que quizá podrían auxiliarnos en la interpretación de los resultados obtenidos: lo relativo a la propiedad y gestión de la explotación; si era abordada de forma única o si existían diferentes concesiones que, a su vez, pudieran diversificar las vías de salida; si los encargos de partidas de material realizados desde diferentes ciudades y obras incluían todas las fases de transporte hasta llegar a destino, lo que podía implicar la elección de puertos fluviales concretos-Naeva-Ilipa-Italica-.

En último término, las rutas óptimas obtenidas deberían ser contrastadas con los modelos hipotéticos de organización y gestión propuestos para la explotación y distribución de los productos desde esta área fuente. De hecho, como insiste Taylor (2015: 495) para el caso concreto que nos ocupa de Almadén, la propuesta de una o varias vías de salida de los productos, dada la posición geográfica diferenciada de cada frente/distrito, tiene importantes implicaciones para la interpretación de las canteras, en su conjunto, como fenómeno económico antiguo. 


\section{Bibliografía}

Adams, C. (2001): "Who bore the burden? The organization of stone transport in Roman Egypt". En MAtTingly, D. y Salmon, J. (eds.): Economies beyond agriculture in the classical world. London: Routledge, pp. 171-192.

Adams, C. (2012): "Transport". En Scheidel, W. (ed.): The Cambridge Companion to the Roman Economy. Cambridge: cup, pp. 218-240.

Àlvarez, A.; Cebrián, R. y RodÀ, I. (2008): "El mármol de Almadén de la Plata y los marmora importados del foro de Segobriga". En Nogales, T. y BelTRÁN, J. (eds.): Marmora Hispana: explotación y uso de materiales pétreos en la Hispania romana. Roma: L'Erma di Bretschneider, pp. 101-120.

Àlvarez, A.; RodÀ, I.; Riera Rullán, M.; Gutiérrez García, A.; Domènech, Á. y Royo, H. (2012): "Provenance of some ancient marbles from El Pla de ses Figueres (Cabrera, Balearic Islands, Spain)". En Gutiérrez García, A.; Lapuente, P. y RodÀ, I. (eds.): Interdisciplinary Studies on Ancient Stone. Proceedings IX ASMOSIA Conference (Tarragona, 2009). Tarragona: ICAC, pp. 426-434.

Anderson, D. (2012): "Least cost pathway analyses in archaeological research: approaches and utility". En White, D. y Surface-Evans, S. (eds.): Least cost analysis of social landscapes: archaeological case studies. Salt Lake City: uup, pp. 239-257.

Bedon, R. (1984): Les carrières et les carriers de la Gaule romaine. Paris: Picard.

Beltrán, J.; Ontiveros, E.; Loza, M. L.; Rodríguez Gutiérrez, O. y TaYlor, R. (2018): "Marmora de procedencia hispana en Baelo Claudia”. En Beltrán, J.; LozA, M. L. y Ontiveros, E. (coords.): Marmora Baeticae. Usos de materiales pétreos en la Bética romana. Estudios arqueológicos y análisis arqueométricos. Sevilla: Univ. de Sevilla, pp. 17-38.

Beltrán, J. y Rodríguez Gutiérrez, O. (2010): “Los materiales lapídeos de la provincia Baetica: estado de la cuestión y líneas actuales de investigación”. En Camporeale, S.; Dessales, H. y Pizzo, A. (eds.): Arqueología de la Construcción II. Los procesos constructivos en el mundo romano: Italia y las provincias occidentales. Mérida: CSIC-IAM, pp. 555- 570.

Beltrán, J.; Rodríguez Gutiérrez, O.; López AldaNa, P.; Ontiveros, E. y Taylor, R. (2012): "Las canteras romanas de Almadén de la Plata (Sevilla)". En García-Entero, V. (ed.): $E l$ marmor en
Hispania: explotación, uso y difusión en época romana. Madrid: UNED, pp. 253-275.

Bevan, A. H. (2011): "Computational models for understanding movement and territory". En MAYORAL, V. y Celestino, S. (eds.): Tecnologías de la información geográfica y análisis arqueológico del territorio: Actas V Simposio Internacional de Arqueología de Mérida. Mérida: CSIC-IAM, pp. 383-394.

Blázquez y Delgado Aguilera, A. y Blázquez JiméNEZ, A. (1921): Vias romanas de Albacete a Zaorejas, de Quero a Aranjuez, de Meaques a Titulcia, de Aranjuez a Toledo y de Ayamonte a Mérida: memoria de los resultados obtenidos en los viajes y excavaciones practicados en 1920 y 1921. Madrid: Tipogr. RABM.

Bonsor, G. E. (1989): Expedición arqueológica a lo largo del Guadalquivir. Écija: Gráficas Sol.

Burford, A. (1960): "Heavy transport in classical antiquity", The Economic History Review, 13 (1), pp. 1-18. https://doi.org/10.2307/2591403

Camacho, M.; Jiménez, A. M.; Oria, M. y Parodi, M. J. (2005): "La ocupación romana en la Sierra Norte de Sevilla: Castilblanco de los Arroyos”, Spal, 14, pp. 281-300.

Canto, A. M. (1977-78): "Avances sobre la explotación del mármol en la Espańa romana”, Archivo Español de Arqueologia, 50-51, pp. 165-188.

CARreras, C. (1994): Una reconstrucción del comercio en cerámicas: la red de transportes en Britannia. Barcelona: Edicions Servei del Llibre L'Estaquirot.

Carreras, C. y De Soto, P. (2010): Historia de la movilidad en la Peninsula Ibérica: redes de transporte en SIG. Barcelona: UOC.

Cisneros, M. (1988): Mármoles hispanos. Su empleo en la España romana. Zaragoza: Univ. de Zaragoza.

Corzo, R. y Toscano, M. (1992): Las vías romanas de Andalucía. Sevilla: Consejería de Obras Públicas y Transportes.

DeLaine, J. (1997): The baths of Caracalla: a study in the design, construction, and economics of large-scale building projects in imperial Rome. Journal of Roman Archaeology, Suppl. Ser., 25. Portsmouth.

Deman, A. (1987): "Réflexions sur la navigation fluvial dans l'antiquité romaine". En Hackens, T. y MarChetTi, P. (eds.): Histoire économique de l'antiquite: bilans et contributions de savants belges présentes dans une réunion interuniversitaire à Anvers/Antwerpen, Universitaire Fakulteiten Sint-Ignatius. Louvain-la-Neuve: Sém. de Numism. Marcel Hoc, pp. 79-106. 
DijKstra, E. (1959): "A note on two problems in connexion with graphs", Numerische Mathematik, 1, pp. 269-271. https://doi.org/10.1007/BF01386390

Domínguez, S. (2008): "Huellas de cantería romana de mármol en Almadén de la Plata (Sevilla), un patrimonio a conservar". En Nogales, T. y Beltrán, J. (eds.): Marmora Hispana: explotación y uso de materiales pétreos en la Hispania romana. Roma: L'Erma di Bretschneider, pp. 377-389.

Duncan Jones, R. (1974): The economy of the Roman Empire: quantitative studies. Cambridge: Cup.

Ericson, J. E. y Goldstein, R. (1980): "Workspace: a new approach to the analysis of energy expenditure within site cachtments". En Findlow, F. J. y ERICson, J. E. (eds.): Cachtment analysis: essays in human resource space. Anthropology UCLA, 10 (1-2). Los Ángeles, pp. 21-30.

Fernández Flores, A. y Carrasco, I. (2013-2014): "Los asentamientos rurales romanos del curso medio del río Viar (Sevilla)”, Romula, 12-13, pp. 95-124.

Fiz, I. y Orengo, H. (2008): "Simulating communications routes in Mediterranean alluvial plains". En Posluschny, A.; Lambers, K. y Herzog, I. (eds.): Layers of perception. Proceedings $35^{\text {th }}$ International Conference on Computer Applications and Quantitative Methods in Archaeology (CAA), (Berlin, 2007). Bonn: R. H. Verlag, pp. 316-321.

Fonte, J.; Parcero, C. y Costa, J. M. (2017): “A Gis-based analysis of the rationale behind Roman roads. The case of the so-called via XVII (Nw Iberian Peninsula)", Mediterranean Archaeology and Archaeometry, 17(3), pp. 163-189. https://doi.org/10.5281/ zenodo. 1005562

García-Entero, V. y Vidal, S. (2007): "Marmora from the Roman site of Carranque (Toledo, Spain)", Marmora, 3, pp. 53-69.

García Sanjuán, L.; Vargas, M. A. y Wheatley, D. (2004): "Prospecciones de superficie en la zona de afección del embalse de Los Melonares (Almadén de la Plata, El Pedroso y Castilblanco de los Arroyos, Sevilla)". En Anuario Arqueológico de Andalucía 2001. Sevilla: Consejería de Cultura, vol. III, pp. 962-972.

García y Bellido, A. (1960): Colonia Aelia Augusta Italica. Madrid: IEA.

García y Bellido, A. (1965): "La Italica de Adriano". En Piganiol, A. y Terrasse, H. (eds.): Les empereurs romains d'Espagne: Madrid-Italica, 1964. Paris: CNRS, pp. 7-26.

Gietl, R.; Doneus, R. y Fera, M. (2008): "Cost distance analysis in an alpine environment. Comparison of cost-surface modules". En Posluschny, A.; LaMBers, K. y Herzog, I. (eds.): Layers of perception. Proceedings $35^{\text {th }}$ Intern. Conference on Computer Applications and Quantitative Methods in Archaeology (CAA), (Berlin, 2007). Bonn: R. H. Verlag, pp. 1-9.

Groenhuijzen, M. y Verhagen, P. (2015): "Exploring the dynamics of transport in the Dutch Limes", eTopoi, 4, pp. 25-47.

Gürmil, A. y Parcero, C. (2015): "Dotting the joins: a non-reconstructive use of Least Cost Paths to approach ancient roads. The case of the Roman roads in the Nw Iberian Peninsula", Journal of Archaeological Science, 54, pp. 31-44. https://doi.org/10.1016/j. jas.2014.11.030

Hernández Díaz, J.; Sancho, A. y Collantes, F. (1955): Catálogo Arqueológico e Histórico de la Provincia de Sevilla. Iv. Sevilla, Diput. Prov. de Sevilla.

Herzog, I. (2013a): "Theory and practice of cost functions”. En Contreras, F.: Farjas, M. y Melero, F. J. (eds.): Fusion of Cultures. Proceedings of the 38th Annual Conference on Computer Applications and Quantitative Methods in Archaeology (CAA) (Granada, 2010). Oxford: Archaeopress, pp. 375-82.

Herzog, I. (2013b): "The potential and limits of Optimal Path Analysis". En Bevan, A. y Lake, M. (eds.): Computational Approaches to Archaeological Spaces. Walnut Creek: Left Coast Press, pp. 179-211.

Herzog, I. y Posluschny, A. (2011): "Tilt-slope-dependent least cost path calculations revisited". En Jerem, E.; Redö, F. y Szeverényi, V. (eds.): On the road to reconstructing the past. Proceedings of the $36^{\text {th }}$ International Conference. Computer Applications and Quantitative Methods in Archaeology (CAA) (Budapest, 2008). Budapest: Archeolingua, pp. 236-242.

Howey, M. C. L. (2011): "Multiple pathways across past landscapes: circuit theory as a complementary geospatial method to least cost path for modeling past movement", Journal or Archaeological Science, 38, pp. 2523-2535.

Jobe, R. y White, P. S. (2009): “A new cost-distance model for human accessibility and a evaluation of accessibility bias in permanent vegetation plots in Great Smoky Mountains National Park, UsA", Journal of Vegetation Science, 20, pp. 1099-1109.

KAY, A. (2012): "Route choice in hilly terrain", Geographical Analysis, 44, pp. 87-108.

Kvamme, K. L. (1992): "Terrain form analysis of archaeological location through Geographic Information System". En Lock, G. y Moffet, J. (eds.): Computer Applications and Quantitative Methods in 
Archaeology 1991 (CAA). Oxford: Archaeopress, pp. 127-136.

LANDELs, J. G. (1981): Engineering in the ancient world. Berkeley: UCP.

LANGmuir, E. (1984): Mountaincraft and leadership: a handbook for mountaineers and hillwalking leaders in the British Isles. Edinburgh: British Mountaineering Council.

Lapuente, P.; Nogales, T.; Royo, H. y Brilli, M. (2014): "White marble sculptures from the National Museum of Roman Art (Mérida, Spain): sources of local and imported marbles", European Journal of Mineralogy, 26 (2), pp. 333-354. https://doi.org/ 10.1127/0935-1221/2014/0026-2369

LeutHÄUSSER, U. (2013): About walking uphill: time required energy consumption and the zigzag transition. https://sigmadewe.com/fileadmin/user_upload/ pdf-Dateien/Bergaufgehen_engl.pdf

Llobera, M. y Sluckin, T. J. (2007): "Zigzagging: theoretical insights on climbing strategies", Journal of Theoretical Biology, 249 (2), pp. 206-217.

Lock, G. y PouncetT, J. (2010): "Walking the ridgeway revisited: the methodological and theoretical implications of scale dependency for the derivation of slope and the calculation of least-cost paths". En Frischer, B.; Webb Crawford, J. y Koller, D. (eds.): Making history interactive. Proceedings of the $37^{\text {th }}$ International Conference on Computer Applications and Quantitative Methods in Archaeology (CAA) (Williamsburg, Virginia, 2009). Oxford: Archaeopress, pp. 192-203.

Márquez, J.; Vallejo, I. y Álvarez Francoso, J. I. (2017): "Estimated travel time for walking trails in natural areas", Geografisk Tidsskrift-Danish Journal of Geography, 117 (1), pp. 53-62. https://doi.org/10.10 80/00167223.2017.1316212

MAyer, M. y RodÀ, I. (1998): "The use of marble and decorative stone in Roman Baetica". En KeAY, S. (ed.): The Archaeology of Early Roman Baetica. Portsmouth: Journal of Roman Archaeology, pp. 217-234.

Minetti, A. E.; Moia, C.; Roi, G. S.; Susta, D. y FeRRETI, G. (2002): "Energy cost of walking and running at extreme uphill and downhill slopes", Journal of Applied Physiology, 93, pp. 1039-1046.

Muñoz, D. (2010): "Sobre el topónimo 'Camino de la Plata' y el eje s-N/N-s del Occidente hispano. Nuevas consideraciones, aportaciones y reflexiones", El Nuevo Miliario, 11, pp. 5-36.

Murrieta-Flores, P. (2011): "Movilidad y vías de paso en los paisajes prehistóricos: megalitos y vías pecuarias en Almadén de la Plata”. En Mayoral, V. y Celestino, S. (eds.): Tecnologías de información geográfica y análisis arqueológico del territorio. Actas del v Simposio Internacional de Arqueología de Mérida. Mérida: CSIC-IAM, pp. 411-423.

Murrieta-Flores, P. (2012): "Understanding human movement through spatial technologies. The role of natural areas of transit in the Late Prehistory of South-western Iberia", Trabajos de Prehistoria, 69, pp. 103-122.

NaIsmith, N. N. (1892): "Cruach Ardran, Stobinian, and Ben More", The Scottish Mountaineering Club Journal, 2, p. 135.

Ontiveros, E. (2008): “Análisis petrográfico de los mármoles de la cantera de la Loma de los Castillejos y su aportación al estudio arqueométrico de las canteras romanas de Almadén de la Plata”. En Nogales, T. y Beltrán, J. (eds.): Marmora Hispana: explotación y uso de materiales pétreos en la Hispania romana. Roma: L'Erma di Bretschneider, pp. 365-376.

Origlia, F.; Gliozzo, E.; Meccheri, M.; Spanenberg, J.; Turbanti, I. y Papi, E. (2011): "Mineralogical, petrographic and geochemical characterisation of white and coloured Iberian marbles in the context of the provenancing of some artefacts from Thamusida (Kenitra, Morocco)", European Journal of Mineralogy, 23 (6), pp. 857-869. https://doi. org/10.1127/0935-1221/2011/0023-2145

Padilla, A. (1998): "Apuntes sobre el comercio y el transporte de mármoles en la Bética de los siglos I-II", Florentia Iliberritana, 9, pp. 283-304.

Pandolf, K. B.; Giboni, G. B. y Goldman, R. F. (1977): "Predicting energy expenditure with loads while standing or walking very Slowly", Journal of Applied Physiology, 43, pp. 577-581.

Pegoretti, G. (1863): Manuale pratico per l'estimazione dei lavori architettonici, stradali, idraulici e di fortificazione per uso degli ingegneri ed'architetti, vol. I. Milano: Tipografia di Domenico Salvi e Comp.

Pingel, T. J. (2010): "Modelling slope as a contributor to route selection in mountainous areas", Cartography and Geographic Information Science, 37, pp. 137148.

Ponsich, M. (1974): Implantation rurale antique sur le bas-Guadalquivir: Seville, Alcalá del Río, Lora del Río, Carmona, vol. 1. Madrid: Casa de Velázquez.

Rademaker, K.; Reid, D. y Bromley, G. (2012): “Connecting the dots. Least cost analysis, paleogeography, and the search for Paleoindian sites in Southern Highland Peru". En White, D. y Surface-Evans, S. 
(eds.): Least cost analysis of social landscapes: archaeological case studies. Salt Lake City: uup, pp. 32-45.

Raepsaet, G. (1984): “Transport de tambours de colonnes du Pentélique à Éleusis au Iv $v^{\mathrm{e}}$ siècle avant notre ère", L'Antiquité Classique, 53, pp. 101-136. https:// doi.org/10.3406/antiq.1984.2115

RaEPSAET, G. (2002): Attelages et techniques de transport dans le monde gréco-romain. Bruxelles: Livre Timperman.

Raepsaet, G. (2010): "Land transport, part 2: riding, harnesses, and vehicles". En Oleson, J. P. (ed.): The Oxford handbook of engineering and technology in the Classical World. Oxford: oup, pp. 580-605.

ReEs, W. G. (2004): "Least-cost paths in mountainous terrain", Computer and Geosciences, 30 (3), pp. 203209.

RodÀ, I. (1997): "Los mármoles de Italica. Su comercio y origen”. En Caballos, A. y León, P. (eds.): Italica MMCC. Actas de las Jornadas MMCC aniversario de la Fundación de Itálica (Sevilla, 1994). Sevilla: Consejería de Cultura, pp. 155-180.

Rodríguez Gutiérrez, O.; Beltrán, J.; López Aldana, P.; Ontiveros, E. y Taylor, R. (2012): “The quarries of Almadén de la Plata (Seville, Spain): new data from the recent archaeological interventions". En Gutiérrez García, A.; Lapuente, P. y RodÀ, I. (eds.): Interdisciplinary Studies on Ancient Stone Proceedings. IX ASMOSIA Conference (Tarragona, 2009). Tarragona: ICAC, pp. 645-650.

Rohault, G. (1874). La Toscane au Moyen Age: Lettres sur l'architecture civile et militaire en 1400. Paris: Morel.

Russell, B. (2013): The economics of the Roman stone trade. Oxford: oup. https://doi.org/10.1093/acprof:oso/9780199656394.001.0001

SaAty, T. (1980): The Analytic Hierarchy Process. New York: McGraw-Hill.

Sillières, P. (1990): Les voies de communication de l'Hispanie méridionale. Paris: Diffusion de Boccard.

Sippel, D. (1987): "Some observations on the means and cost of the transport of bulk commodities in the Late Republic and Early Empire", Ancient World, 16, pp. 35-45.

Soule, R. G. y Goldman, R. F. (1972): "Terrain coefficients for energy cost prediction", Journal of Applied Physiology, 32 (5), pp. 706-708.

TAYLOR, R. (2018): “Análisis formal de las evidencias de explotación antigua en la Loma de los Castillejos de Almadén de la Plata (Sevilla)". En Gutiérrez García, M. A. y Rouillard, P. (coords.): Lapidum natura restat: canteras antiguas de la península ibérica en su contexto (cronología, técnicas y organización de la explotación). Tarragona-Madrid: ICAC-Casa de Velázquez, pp. 95-108.

Tobler, W. (1993): Three presentations on geographical analysis and modeling: non-isotrophic geographic modeling; speculations on the geometry of geography; and global spatial analysis. Technical Report, 93-1. Santa Barbara: NCGIA.

Tomlin, C. D. y Berry, J. K. (1979): "Mathematical structure for cartographic modeling in environmental analysis". En Proceedings of the American Congress on Surveying and Mapping annual meeting. Washington: ACSM, pp. 269-283.

Tripcevich, N. (2009): "Viewshed and cost distance". En Working with archaeological data in ArcMap 9.2. Practical Workshop. https://mapaspects.org/book/export $/ \mathrm{html} / 3743 /$

Verhagen, P. y Jeneson, K. (2012): “A Roman puzzle. Trying to find the via Belgica with GIS". En ChrYsanthi, A.; Murrieta, P. y Papadopoulos, C. (eds.): Thinking beyond the tool: archaeological computing \& the interpretive process. Oxford: Archaeopress, pp. 123-130.

Verhagen, P.; Nuninger, L. y Groenhuijzen, M. R. (2019): "Modelling of pathways and movement networks in archaeology: an overview of current approaches". En Verhagen, P.; Joyce, J. y GroenHuIJZEN, M. R. (eds.): Finding the Limits of the Limes: Modelling Demography, Economy and Transport on the Edge of the Roman Empire. Cham: Springer, pp. 217-249, https://doi.org/10.1007/978-3-03004576-0_11

Wheatley, D.; García Sanjuán, L.; Murrieta, P. y MÁrquez, J. (2010): "Approaching the landscape dimension of the Megalithic phenomenon in Southern Spain", Oxford Journal of Archaeology, 29, pp. 387-405. https://doi.org/10.1111/j.14680092.2010.00354.x

White, D. A. (2012): "Prehistoric trail networks of the western Papaguería: a multifaceted least cost graph theory analysis". En Least Cost Analysis of Social Landscapes: Archaeological Case Studies. Salt Lake City: uup, pp. 188-206. 